\title{
General deformation behavior of deep excavation support systems: A review
}

\author{
Maher T. El-Nimr ${ }^{1}$, Ali M. Basha ${ }^{2}$, Mohamed M. Abo-Raya ${ }^{1}$ and Mohamed H. Zakaria ${ }^{2, *}$ \\ ${ }^{1}$ Civil Engineering Department, Faculty of Engineering, Menoufia University, Egypt. \\ ${ }^{2}$ Civil Engineering Department, Faculty of Engineering, Kafrelsheikh University, Egypt.
}

Global Journal of Engineering and Technology Advances, 2022, 10(01), 039-057

Publication history: Received on 02 December 2021; revised on 05 January 2022; accepted on 07 January 2022

Article DOI: https://doi.org/10.30574/gjeta.2022.10.1.0181

\begin{abstract}
In geotechnical engineering, ground movement caused by excavations is a challenging issue. The excessive differential settlement generated by soil movement induced by wall deflection may cause damage to nearby structures. A detailed literature review on the general deformation behavior of deep excavation support systems is presented in this paper. Many factors, such as normalized horizontal deflection $\left(\delta_{\mathrm{h} \text {-max }} / \mathrm{H}_{\mathrm{e}} \%\right)$, vertical displacement $\left(\delta_{\mathrm{v} \text {-max }} / \mathrm{H}_{\mathrm{e}} \%\right), \delta_{\mathrm{vmax}} / \delta_{\mathrm{hmax}}$ ratio, settlement influence zone $\left(\mathrm{D}_{0}\right)$, etc., can play significant roles in describing the deflection behavior of the excavation system. A descriptive analysis of the reviewed data was carried out. The concluded $\delta_{\mathrm{h}-m a x} / \mathrm{H}_{\mathrm{e}} \%$ values range between 0.17 to 1.5 , with a mean value of 0.58 for soft clay, while in the case of sands and stiff clay soils $\delta_{\mathrm{h}-\mathrm{max}} / \mathrm{H}_{\mathrm{e}} \%$ value ranges between 0.07 to 0.40 , with a mean value of 0.20 . $\delta_{\mathrm{v} \text {-max }} / \mathrm{H}_{\mathrm{e}} \%$ values range between 0.13 to 1.10 , with a mean value of 0.49 for soft soil, while its value ranges between 0.02 to 1.10 , with a mean value of 0.24 in the case of sands and stiff clay soils. The settlement influence zone $\left(D_{0}\right)$ reaches a mean distance of $2.3 \mathrm{H}_{\mathrm{e}}$, which falls within $\mathrm{D}_{0}=1.5$ $3.5 \mathrm{H}_{\mathrm{e}}$ in the case of soft clays, while $\mathrm{D}_{\mathrm{o}}$ reaches a mean distance of $2.0 \mathrm{H}_{\mathrm{e}}$ and $3.0 \mathrm{H}_{\mathrm{e}}$ in the case of sands and other stiff clay soils, respectively. The relationship between system stiffness and excavation-induced wall and ground movements was discussed. Unfortunately, the literature review offers limited data regarding system stiffness, the 3-D nature of excavation support systems, excavation process es, and time effects.
\end{abstract}

Keywords: Deep excavation; Lateral deformation; Ground movement; Engineering

\section{Introduction}

Retaining systems can be classified according to several different criteria: construction method (fill or cut systems), load support mechanism (externally or internally stabilized systems), system stiffness (rigid or flexible systems), stability mechanism, applications, and lifespan (permanent or temporary systems) [1]. Based on load support mechanism, O' Rourke and Jones classified the retaining systems into three main categories: Internally Stabilized Systems (ISS), Externally Stabilized Systems (ESS), and Hybrid Systems (HS) [2]. Clayton et al. also provide a classification of various types of retaining systems based on stability mechanisms [3]. They categorized them into three groups: gravity, embedded, and composite/hybrid walls. Commonly utilized embedded wall types involve, Diaphragm Wall (DW), Sheet Pile Wall (SHPW), Contiguous Pile Wall (CPW), and Secant Pile Wall (SPW) [4-5].

During excavation, the stresses in the earth mass fluctuate due to excavation activities [6-10]. These changes are manifested by lateral wall deformations and ground surface settlements and these movements can describe the performance of excavation support systems [11]. According to Zapata-Medina [7], Moormann [12], Kung et al. [13], Wang et al. [14], Goh [15], Zhang et al. [16], Zhao et al. [17], and others, the lateral wall deformations and ground surface settlements are strongly connected to factors such as (1) soil type and condition; (2) excavation geometry; (3) basal heave stability; (4) earth pressures; (5) type of retaining wall and its construction material; (6) wall stiffness/rigidity

\footnotetext{
${ }^{*}$ Corresponding author: Mohamed H. Zakaria

Civil Engineering Department, Faculty of Engineering, Kafrelsheikh University, Egypt.

Copyright (C) 2022 Author(s) retain the copyright of this article. This article is published under the terms of the Creative Commons Attribution Liscense 4.0.
} 
(7) spacing and stiffness of the struts/supports; (8) construction method; (9) time effects ; (10) workmanship; (11) soil stiffness; (12) adjacent loads; (13) embedded depth; (14)and soil consolidation, creep, and preloading. Cheng et al. [18] mentioned that additional factors caused by natural phenomena, such as erosion in front of the excavation system or an increase in the level of the soil behind the system, may affect the overall deformation behavior of the system. Also, the water pressures must be considered when designing deep excavations for basements below the water table [19-20]. Excavation activities are often divided into three stages based on the relation between the design level and natural level: (1) retaining wall construction, (2) excavation of soil mass and installation of lateral support components, and (3) removing lateral supports and backfill if necessary.

Clough and O'Rourke [21] suggested profiles of lateral wall deformation and the ground surface movement behind it due to excavation activities, as illustrated in Fig. (1). During the initial stages of excavation and before installing the lateral supports, the wall will be deformed as a cantilever, as shown in Fig. (1a). Settlements were represented by a triangular-shaped distribution at this stage, where the maximum settlement value was recorded extremely close to the wall head. While the excavation progresses to deeper heights, lateral supports are placed to limit upper wall head movement. Deep inward wall movements occur during this stage (Fig. 1b). The cumulative wall and ground movements arise from the combination of cantilever and deep inward profiles, as shown in Fig. (1c). Boone and Westland [22] reached the same conclusion on the effect of wall deformation.

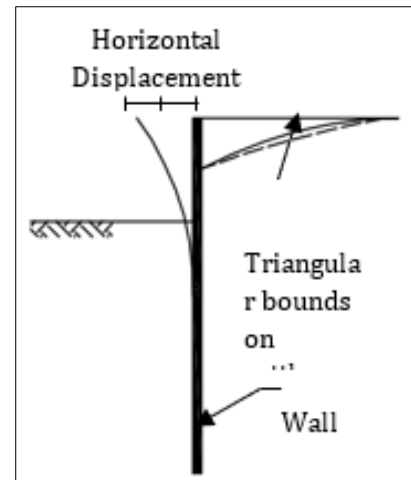

a) Cantilever Profile

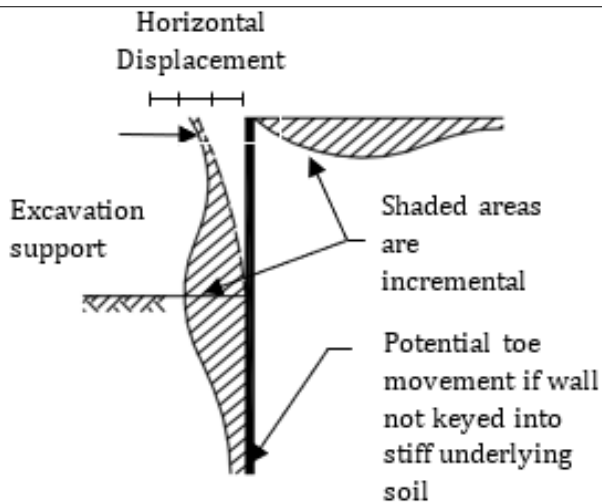

b) Deep Inward Profile

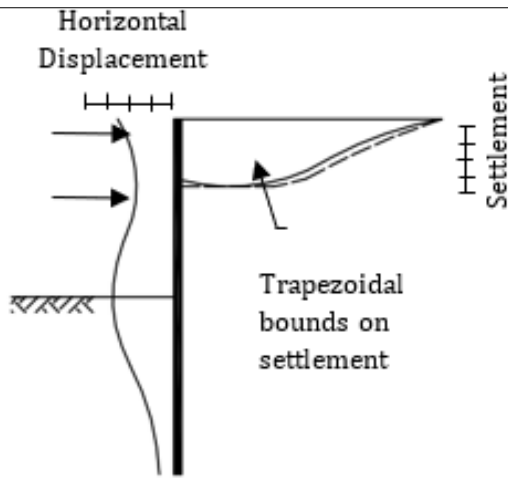

c) Cumulative Profile

Figure 1 Proposed profiles of lateral wall deformation and vertical ground settlement due to excavation activities [21]

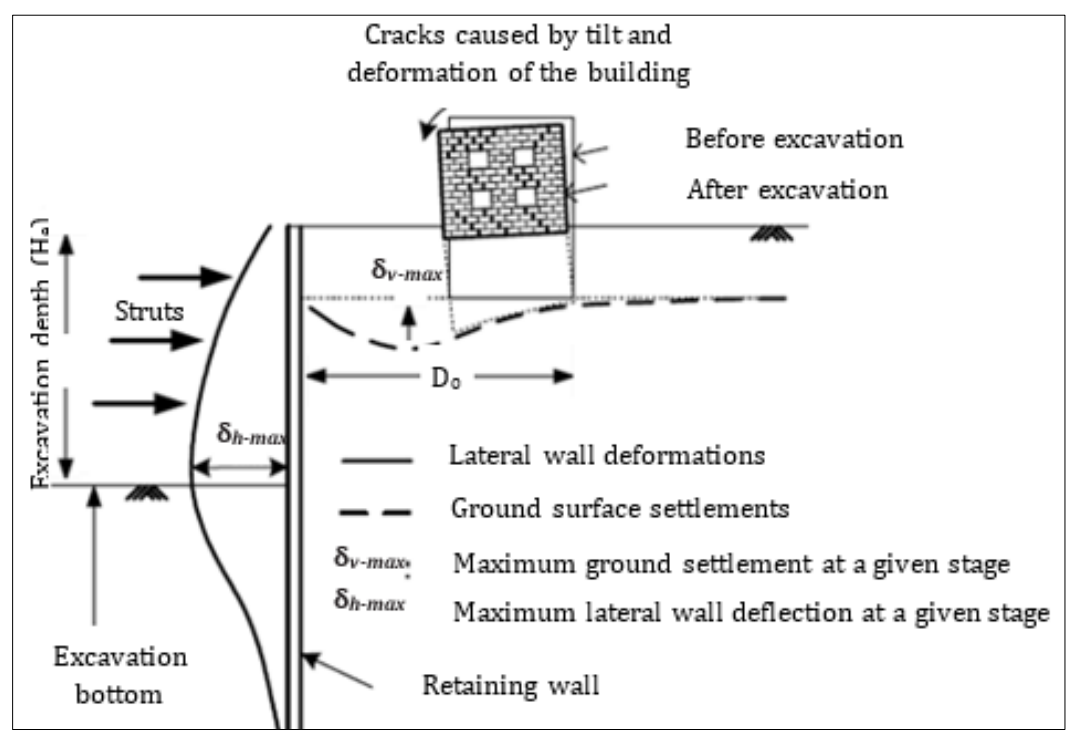

Figure 2 Wall, ground, and adjacent building deformations induced by an excavation [25].

Based on Clough and O'Rourke's study results [21], when deep inward movements are the predominant type of wall deformation due to excavation activities in soft to medium clay, the ground settlement behind the wall may be 
represented by a trapezoidal profile. Settlements usually follow a triangle shape when cantilever movements dominate, in addition, they might follow the same pattern in excavations in sands and stiff clays [21]. Similar conclusions were drawn by Ou et al. [23] and Hsieh and Ou [24], who suggested the Spandrel and Concave settlement profiles based on several case studies in clay soil. It should be mentioned that Fig. 1 only outlines general lateral wall deformation and ground surface settlement behavior due to excavation activities and omits significant factors, such as soil conditions, construction methods, soil stiffness, wall stiffness, and adjacent loads. All the aforementioned factors can considerably affect the value and the pattern of lateral wall deformation as well as ground surface settlement. Generally, Fig. 2 depicts typical excavation-induced wall, ground, and adjacent building deformations according to Hsiao [25]. It can be seen that the adjacent structures may be affected by the severe differential settlement resulting from the ground settlement due to lateral wall deformation. Such potential effect is magnified when deep excavation occurs in a densely populated urban area where excavation activities are carried out adjacent to the structures [26].

\subsection{Excavation Support System Stiffness}

System stiffness is related to several factors such as the wall cross section's flexural rigidity; the embedment depth $\left(\mathrm{H}_{\mathrm{e}}\right)$; spacing between vertical and horizontal supports; base heave stability; structural stiffness of the supports/struts; the efficiency and type of the lateral support connections [27-28]. In many of the previous studies, the stiffness of the retaining system was identified as a significant influencing factor in determining the performance of deep excavation systems. However, according to the analysis of collected data from several case studies, Clough and 0'Rourke [21] concluded that wall stiffness and lateral supports spacing have a limited effect on the expected deformations in the case of hard /stiff clay, on the grounds that base heave stability is rarely a concern. Long [29] concluded that the wall stiffness does not affect the deformation if the excavation has a factor of safety against basal heave more than 3. Also, Moormann [12] reached the same conclusion as Long [29].

According to Strom and Ebeling [30], secant, tangent, and contiguous pile walls; diaphragm walls; slurry walls; concrete walls are considered rigid/stiff support systems. While sheet-pile, soldier beam, and lagging systems are considered flexible support systems. But on the other hand, the majority of walls are subjected to both rigid and flexible body deformation, as they are not totally rigid or flexible [3]. Steel sheet pile walls are well-known for their flexibility, despite that diaphragm walls or braced walls will also flex considerably when they are used to support deep excavations. For example, when lateral supports are placed, the strutted, or braced wall which constructed for the purpose of restricting the movement of the soil beneath adjacent structures will start making only little lateral movements at the support levels, but the wall will then flex between them. However, during and after the wall construction stages, it's unavoidable that the wall will deform horizontally [3].

\section{Objectives and approach method}

The main purpose of this paper is to estimate potential soil and wall deformations because of deep excavation activities in urban areas with varying soil types and support system stiffness. Moreover, the review aims to synthesize the data from papers and case studies around the world This may provide a resource that other researchers can use for their own purposes. To achieve these purposes, all reasonably accessible sources were used to gather and evaluate the data from worldwide experience. Statistical analysis of the collected data will be carried out.

\section{Lateral wall deformations}

Soil type and characteristics, excavation depth, excavation geometry (3-D behavior), lateral supports stiffness, and wall stiffness all contribute to the value of maximum deformation and shape of lateral wall deformation pattern [7,26]. According to Azzam and Elwakil [4], Ramadan et al. [5], and Ramadan and Meguid [26], the increase of the embedded depth of the wall and wall stiffness shall reduce horizontal wall movement.

A study by Hefny et al. investigated the three-dimensional behavior of the deep excavation support system of the underground metro station of Rod El Farrag (Egypt) [10]. Good agreement was obtained between the lateral wall deformations $\left(0.11 \% \mathrm{H}_{\mathrm{e}}\right)$ and the practical approach provided by Clough and O'Rourke [21]. This confirms the effectiveness of the practical approach suggested by Clough and O'Rourke [21].

Based on well documented, Table 1 summarizes the study authors, soil type and state, wall type and construction method, support type, number of cases, and average values of the maximum lateral displacement of a wall ( $\left.\delta_{\mathrm{h}-m a x}\right)$ normalized by the excavation depth $\left(\mathrm{H}_{\mathrm{e}}\right)$, as measured in worldwide case studies. 
Table 1 Summary of reported $\delta_{\mathrm{h}-\max } / \mathrm{H}_{\mathrm{e}}$ values in worldwide case studies

\begin{tabular}{|c|c|c|c|c|c|c|}
\hline Study & \multicolumn{2}{|c|}{ Soil Type and State } & $\begin{array}{l}\text { Wall Type and } \\
\text { Construction } \\
\text { Method }\end{array}$ & $\begin{array}{l}\text { Support } \\
\text { Type }\end{array}$ & $\begin{array}{l}\text { Num. } \\
\text { of } \\
\text { Cases }\end{array}$ & $\begin{array}{c}\text { Aver. } \\
\delta_{h-\max } / H_{e}(\%)\end{array}$ \\
\hline $\begin{array}{l}\text { Mana and Clouh } \\
\text { [31] }\end{array}$ & \multicolumn{2}{|c|}{$\begin{array}{l}\text { Saturated soft to } \\
\text { medium clay }\end{array}$} & SHPW & $\begin{array}{l}\text { Flexible } \\
\text { Support }\end{array}$ & 10 & 1.32 \\
\hline Ou et al. [32] & \multicolumn{2}{|c|}{ Soft clay } & $\mathrm{DW}^{*}$ & - & 10 & 0.4 \\
\hline \multirow{2}{*}{ Masuda [33] } & \multirow{2}{*}{\multicolumn{2}{|c|}{ Clay }} & $\mathrm{DW}^{* *}$ & \multirow{2}{*}{ Mixed support } & 17 & 0.2 \\
\hline & & & $\mathrm{DW}^{*}$ & & 21 & 0.23 \\
\hline \multirow{2}{*}{ Wong et al. [34] } & \multirow{2}{*}{\multicolumn{2}{|c|}{$\begin{array}{l}\text { Stiff residual soils and } \\
\text { weathered rocks }\end{array}$}} & $\begin{array}{l}\text { DW and CPW (with } \\
\text { struts/anchors) }\end{array}$ & Rigid Support & 24 & 0.16 \\
\hline & & & $\begin{array}{l}\text { SPW (with } \\
\text { struts/anchors) }\end{array}$ & Mixed support & 13 & 0.23 \\
\hline \multirow{2}{*}{ Bentler [35] } & \multicolumn{2}{|c|}{ Sand, hard clay } & \multirow{2}{*}{$\mathrm{Cl}_{1}$} & \multirow{2}{*}{ Mixed support } & 1 & 0.19 \\
\hline & \multicolumn{2}{|c|}{ Soft to stiff clay } & & & 1 & 0.45 \\
\hline Long [29] & \multicolumn{2}{|c|}{ Stiff soils } & $\begin{array}{l}\text { DW, CPW, SHPW, and } \\
\text { SPW }^{*}\end{array}$ & Mixed support & 296 & $0.05-0.25$ \\
\hline \multirow{2}{*}{ Moormann [12] } & \multicolumn{2}{|c|}{ Soft soil $(\mathrm{cu}<75 \mathrm{kPa})$} & \multirow{2}{*}{-} & \multirow{2}{*}{ Mixed support } & \multirow{2}{*}{530} & $0.5-1.0(0.87)$ \\
\hline & \multicolumn{2}{|c|}{ Non-cohesive soil } & & & & 0.25 \\
\hline \multirow{2}{*}{$\begin{array}{l}\text { Leung and } \mathrm{Ng} \\
{[36]}\end{array}$} & \multirow{2}{*}{$\begin{array}{l}\text { Silty } \\
\text { sand }\end{array}$} & $\mathrm{A}(\mathrm{N} \leq 30)$ & \multirow{2}{*}{$\mathrm{CW}$} & \multirow{2}{*}{ Rigid support } & \multirow{2}{*}{14} & 0.23 \\
\hline & & $\mathrm{B}(\mathrm{N}>30)$ & & & & 0.13 \\
\hline Kung et al. [13] & \multicolumn{2}{|c|}{ Soft clay } & $\mathrm{DW}^{* *}$ & Rigid Support & 7 & 0.39 \\
\hline \multirow{3}{*}{ Wang et al. [14] } & \multirow{3}{*}{\multicolumn{2}{|c|}{ Soft clay }} & DW and $\mathrm{CPW}^{* *}$ & Rigid Support & 32 & 0.17 \\
\hline & & & $\begin{array}{l}\text { DW, CPW, and } \\
\text { compound DSM }\end{array}$ & Mixed support & 200 & 0.40 \\
\hline & & & $\begin{array}{l}\text { SHPW (with internal } \\
\text { strut/anchors }\end{array}$ & $\begin{array}{l}\text { Flexible } \\
\text { Support }\end{array}$ & 11 & 1.50 \\
\hline Li et al. [37] & \multicolumn{2}{|c|}{ Silty clay } & DW & Rigid Support & 30 & 0.2 \\
\hline Cetin [38] & \multicolumn{2}{|c|}{ Soft clay } & $\begin{array}{l}\text { SNSW, CPW, MPW, } \\
\text { DW, CW, and SPW. }\end{array}$ & Mixed support & 28 & 0.18 \\
\hline $\begin{array}{l}\text { Zhang and Goh } \\
\text { [39] }\end{array}$ & \multicolumn{2}{|c|}{ Residual soils } & DW with 4 struts. & Rigid Support & 2 & $<0.1$ \\
\hline $\begin{array}{l}\text { Hsiung et al. } \\
{[40]}\end{array}$ & \multicolumn{2}{|c|}{$\begin{array}{l}\text { Loose to medium dense } \\
\text { sands }\end{array}$} & $\mathrm{DW}^{*}$ & Rigid Support & 1 & 0.32 \\
\hline $\begin{array}{l}\text { Ali and Khan } \\
{[41]}\end{array}$ & \multicolumn{2}{|c|}{ Stiff clay } & Anchored PW & Mixed support & 35 & $\begin{array}{c}0.40(0.1 \text { to } \\
0.7)\end{array}$ \\
\hline $\begin{array}{l}\text { Zhang et al. } \\
\text { (2018) [16] }\end{array}$ & $\begin{array}{l}\text { Bukit } \\
\text { residu }\end{array}$ & $\begin{array}{l}\text { mah granite } \\
\text { oil }\end{array}$ & DW and SPW & Rigid Support & 4 & $\begin{array}{l}0.072(0.025 \\
\quad \text { to } 0.15)\end{array}$ \\
\hline Xiao et al. [42] & Soft s & & $\begin{array}{l}\text { DW, CPW, SMW, and } \\
\text { SHPW. }\end{array}$ & Mixed support & 92 & $\begin{array}{c}0.2(0.05 \text { to } \\
0.55)\end{array}$ \\
\hline $\begin{array}{l}\text { Hefny et al. } \\
(2020)[10]\end{array}$ & $\begin{array}{l}\text { Sandy } \\
\text { dense }\end{array}$ & $\begin{array}{l}\text { y clay - very } \\
\text { ine sand }\end{array}$ & DW & Rigid Support & 1 & 0.11 \\
\hline
\end{tabular}

\section{Ground movement predictions for areas adjacent to excavations}

In general, extensive excavation has two major impacts on the surrounding soil. Firstly, the removal of the weight of excavated material reduces vertical stress in the soil under the excavation level [43]. Secondly, the removal of the inner 
soil from the excavation pit causes the soil around the excavation pit to lose its lateral stability [43]. Consequently, the major aim of excavation support systems lateral is to give essential lateral support for the soil surrounding the excavation area to avoid or at least significantly minimize the associated motions [44]. So, deep excavations trigger both lateral deformation and vertical ground settlement because of the stress relaxation and bottom heave. Also, the kinetic loading of nearby structures and subterranean facilities, as well as the proximity of the structures to the excavation region, are all factors which influence the resultant ground deformations (value and shape) [7, 10, 43].

In the following sections, vertical ground deformations behind the wall will be classified into two directions: (1) perpendicular profile; (2) parallel profile and corner effect.

\subsection{Perpendicular Profile}

Peck presented the first effective method for predicting the ground surface settlement adjacent to excavation (value and shape) [45]. data from ground surface settlements adjacent to temporarily braced sheet-pile and soldier pile walls with lower system stiffness were used to develop this approach. As illustrated in Fig. 3, Clough and 0'Rourke [21] established settlement profiles according to soil type for predicting ground settlement behind the excavation system. If the maximum surface settlement is known, the non-dimensional profiles in Fig. 3 could be utilized to predict the surface settlement profile.

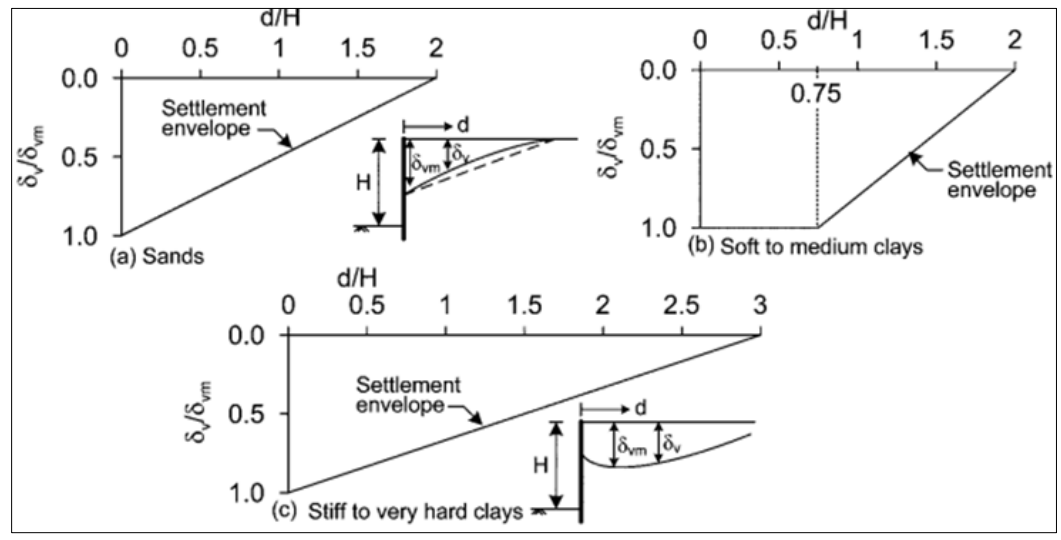

Figure 3 Suggested schemes for predicting the shape of the vertical ground surface settlement adjacent to the excavation region [21].

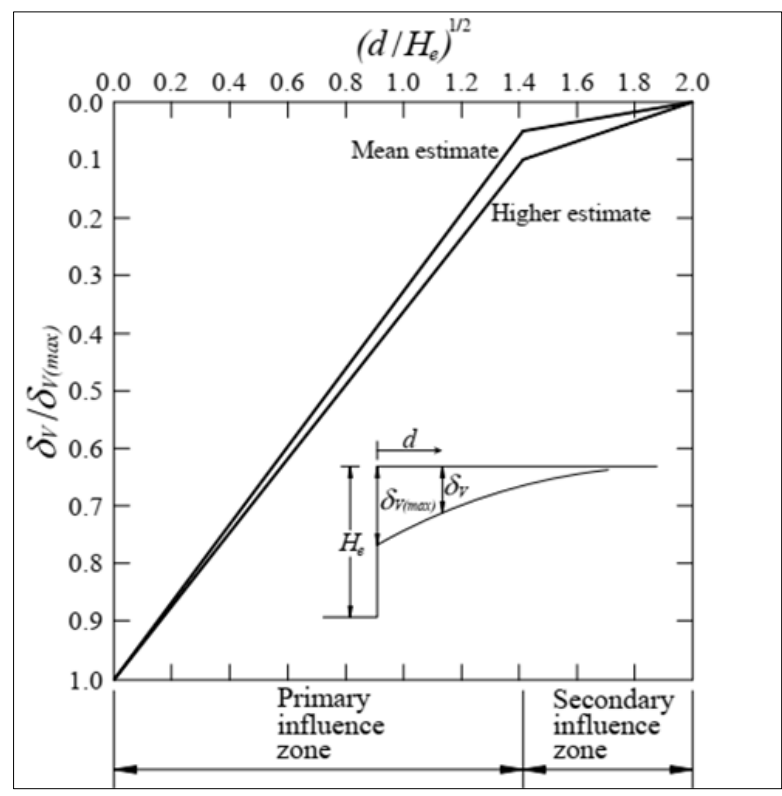

Figure 4 The proposed Spandrel Settlement Profile (SSP) according to Ou et al. [32]. 
Ou et al. [32] provided a technique which utilized for predicting the ground movement profile behind the retaining wall. The proposed technique was developed through the investigation of ten soft soil case studies (Taipei, Taiwan). In light of the collected data, they developed a trilinear settlement profile (Fig. 4) termed Spandrel-Type Settlement (SSP), which demonstrates that the largest settling occurs extremely close to the wall. Furthermore, this sort of settlement profile arises when there is a significant level of wall deflection during the early phase of excavation when cantilever conditions occur. As shown in Fig. 4 , a relationship between $\delta_{\mathrm{v}} / \delta_{\mathrm{v}-\text { max }}$, where $\delta_{\mathrm{v} \text {-max }}$ is the maximum ground surface settlement behind the wall versus the square root of the distance from the edge of the wall head, d, divided by the excavation depth, $\mathrm{H}_{\mathrm{e}}$.

Based on nine case studies across the world, Hsieh and Ou [24] expanded the work of Ou et al. [32] by putting forward the Concave Settlement Profile (CSP), as illustrated in Fig. 5. The greatest settlement occurs at a distance of $\left(\mathrm{H}_{\mathrm{e}} / 2\right)$ from the wall, as shown in Fig. 5 , and the settlement near the wall may be approximated to $0.5 \delta_{\mathrm{v} \text {-max. }}$.

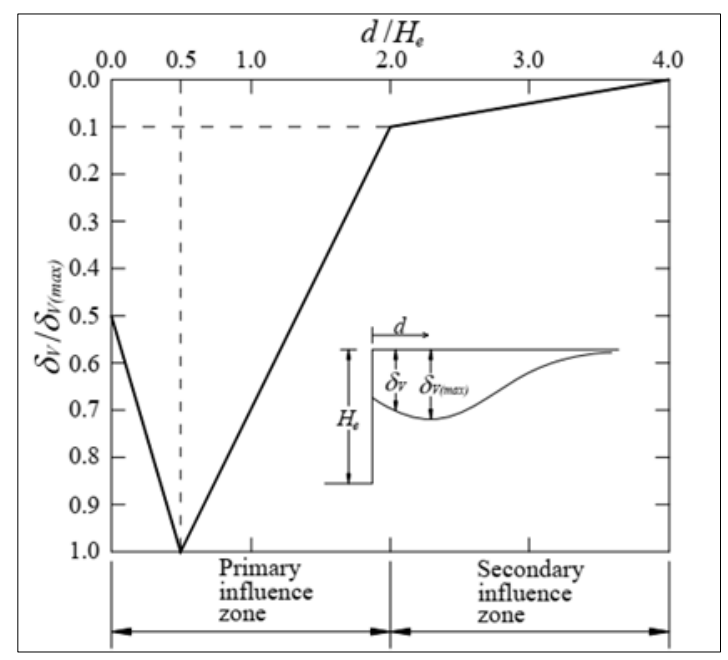

Figure 5 The proposed Concave Settlement Profile (CSP) [24].

Additionally, Hsieh and $\mathrm{Ou}$ [24] developed a relation between the cantilever movement stage and deep inward movement stage of wall deflection, comparable to O'Rourke [46], as a preliminary estimate for predicting the kind of settlement profile. They recommended the following methodology for identifying the appropriate ground surface settlement profile: (1) calculate the magnitude of lateral wall deformation using finite element or any acceptable method; (2) Compute the areas of the cantilever and the inward bulging according to the wall deformation profile in order to identify the kind of settlement profile.; (3) calculate the magnitude of $\delta_{\mathrm{v} \text {-max }}$ according to the following relationship: $\delta_{\mathrm{v}-\max }=0.5 \delta_{\mathrm{h}-\max }$ to $1.0 \delta_{\mathrm{h}-\max }$; and (4) choose and plot the ground surface settlement profile using Fig. 4 for SSP type, or Fig. 5 for CSP type. Also, for predicting ground surface settlement profile, and $\delta_{\mathrm{v} \text {-max }}$ during excavations in soft to medium clay soils, a simplified semi-empirical model was provided by kung et al. [13] as presented in Fig. 6 . As shown in Fig. 6, there is some convergence between the proposed profiles presented by kung et al. [13], and Hsieh and Ou [24].

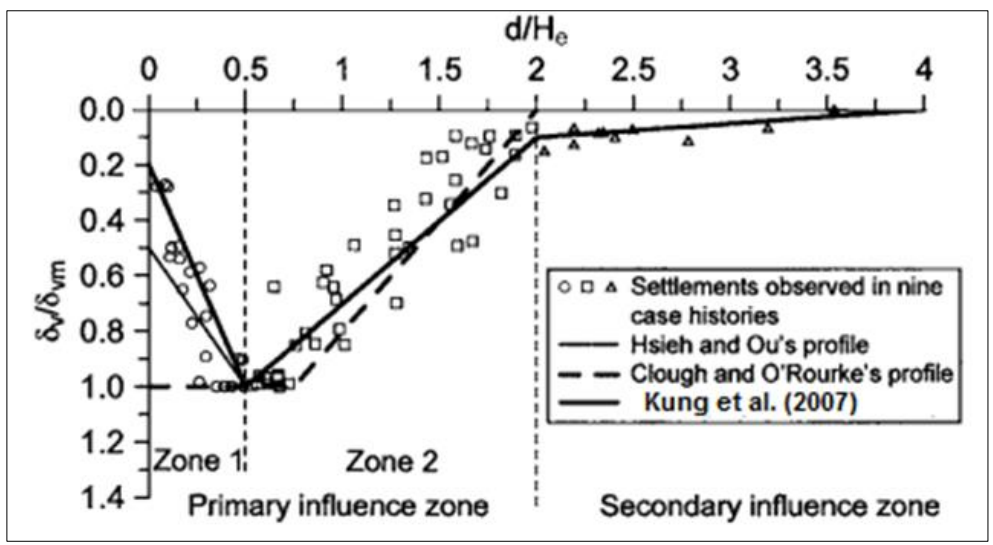

Figure 6 The proposed ground surface settlement profile according to kung et al. [13] and others 
Wang et al. compiled and evaluated a large database of 300 case studies on lateral wall deformations and ground surface settlements caused by deep excavations activities in Shanghai soft soils [14]. They concluded that the more the excavation depth increases, the higher the value of maximum ground surface settlement shall be. The average value of $\delta_{v-\max }$ is $0.42 \% \mathrm{H}_{\mathrm{e}}$, with values ranging from $0.1 \% \mathrm{H}_{\mathrm{e}}$ to $0.8 \% \mathrm{H}_{\mathrm{e}}$. As shown in Fig. 7 , a relationship between $\delta_{\mathrm{v}} / \delta_{\mathrm{v}-\mathrm{max}}$, versus the distance from the edge of the wall head, $d$, divided by the excavation depth, He. Generally, wang et al. [14] presented a simplified surface ground settlement profile which is considered a highly overestimated prediction method.

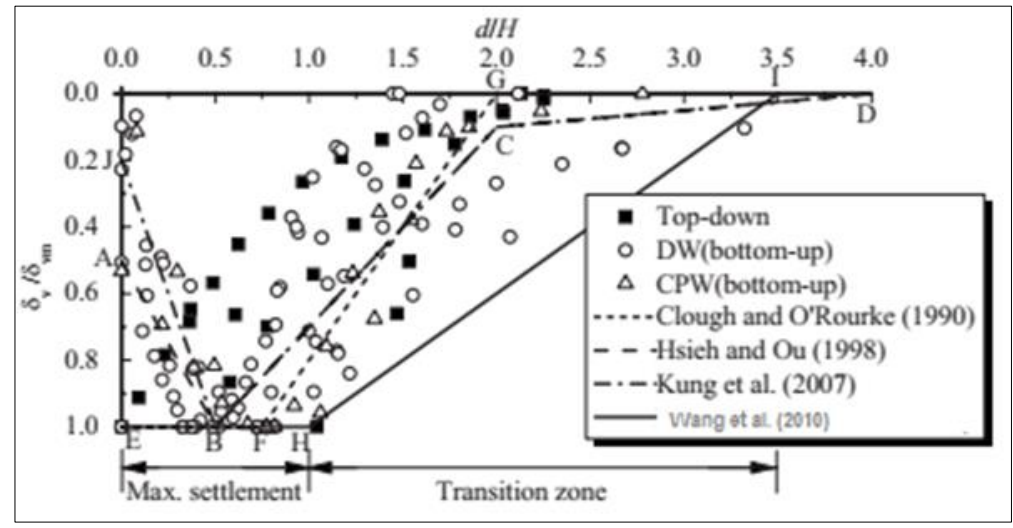

Figure 7 Proposed ground surface settlement profile according to Wang et al. [14] and others

Hefny et al. examined the 3D behavior of the supported deep excavation of Rod El Farrag underground station (Egypt) [10]. The ground surface settlement profile adjacent to the excavation in this case study agreed well with Hsieh and Ou's [24] practical approach.

Based on well documented, Table 2 summarizes the study authors, soil type, support type, number of cases, and average values of the maximum vertical settlement of a wall $\left(\boldsymbol{\delta}_{\mathbf{v} \text {-max }}\right)$ normalized by the excavation depth $\left(\mathrm{H}_{\mathrm{e}}\right)$, as reported in case studies around the worldwide.

Table 2 Summary of reported $\delta_{\mathrm{v} \text {-max }} / \mathrm{He}_{\mathrm{e}}$ values

\begin{tabular}{|c|c|c|c|c|}
\hline Study & \multicolumn{2}{|c|}{ Soil Type } & Support type & $\delta_{v-\max } / H_{e}(\%)$ \\
\hline Peck [45] & \multicolumn{2}{|c|}{ Sands; medium to hard clays } & Flexible Support & $<1.0$ \\
\hline Clough and O'Rourke [21] & \multicolumn{2}{|c|}{ Stiff soil/sands } & Mixed support & Aver. 0.15 \\
\hline Ou et al. [32] & \multicolumn{2}{|l|}{ Soft clay } & - & $0.13-0.36$ \\
\hline Fernie and Suckling [47] & \multicolumn{2}{|l|}{ Stiff soil } & Mixed support & Aver. 0.15 \\
\hline Wong et al. [34] & \multicolumn{2}{|l|}{ Soft clay } & - & $0.04-0.20$ \\
\hline \multirow{2}{*}{ Bentler [35] } & \multicolumn{2}{|c|}{ Sand/hard clay } & \multirow{2}{*}{ Mixed support } & Aver. 0.22 \\
\hline & \multicolumn{2}{|c|}{ Soft to stiff clay } & & Aver. 0.55 \\
\hline Long [29] & \multicolumn{2}{|l|}{ Stiff soil } & Mixed support & $<0.20$ \\
\hline Li [48] & \multicolumn{2}{|l|}{ Soft clay } & Rigid support & $0.20-0.70(0.47)$ \\
\hline \multirow{2}{*}{ Moormann [12] } & \multicolumn{2}{|l|}{ Soft soil } & \multirow{2}{*}{ Mixed support } & $0.1-10(1.10)$ \\
\hline & \multicolumn{2}{|c|}{ Non-cohesive Soils } & & 0.27 \\
\hline \multirow{2}{*}{ Leung and Ng [36] } & \multirow{2}{*}{ Silty sand } & $A(N \leq 30)$ & \multirow{2}{*}{ Rigid support } & $0.06-0.22(0.12)$ \\
\hline & & $\mathrm{B}(\mathrm{N}>30)$ & & $0.01-0.04(0.02)$ \\
\hline Wang et al. [14] & \multicolumn{2}{|l|}{ Soft soil } & Mixed support & 0.42 \\
\hline Wang et al. [49] & \multicolumn{2}{|l|}{ Soft soil } & Mixed support & $0.10-0.80(0.38)$ \\
\hline
\end{tabular}




\begin{tabular}{|l|l|l|l|}
\hline Li et al. [37] & Silty clay & Rigid Support & $0.04-0.19$ \\
\hline Ali and Khan [41] & Firm to stiff clay & Mixed support & $0.10-0.40$ \\
\hline Zhang et al. [16] & Residual soil & Rigid Support & $0.09-0.9(0.27)$ \\
\hline Xiao et al. [42] & Soft soils & Mixed support & $0.05-0.7(0.23)$ \\
\hline Hefny et al. [10] & Sandy silty clay and dense to fine sand & Rigid Support & Aver. 0.15 \\
\hline
\end{tabular}

Table 3 compares the locations of the maximum ground surface settlement $\left(\boldsymbol{U}_{\boldsymbol{v}-\mathrm{max}}\right)$ in terms of excavation depth $\left(\mathrm{H}_{\mathrm{e}}\right)$, as measured in worldwide case studies.

Table 3 Summary of the reported locations of the maximum ground surface settlement

\begin{tabular}{|c|c|c|c|c|}
\hline Study & Soil Type & Support Type & $\begin{array}{c}\text { Number of } \\
\text { Cases }\end{array}$ & $\begin{array}{l}\text { Average } U_{v-m a x} \\
\text { location }\end{array}$ \\
\hline Hsieh and Ou [24] & Soft soil & Mixed support & 9 & $0.5 \mathrm{H}_{\mathrm{e}}$ \\
\hline \multirow{2}{*}{ Moormann [12] } & Soft soil & \multirow{2}{*}{ Mixed support } & 159 & $\leq 2.0 \mathrm{He}_{\mathrm{e}}$ \\
\hline & Other soils & & 371 & $\leq 0.5 \mathrm{H}_{\mathrm{e}}$ \\
\hline Wang et al. [14] & Soft soil & Mixed support & 300 & $1.0 \mathrm{H}_{\mathrm{e}}$ \\
\hline Zhang et al. [16] & Bukit Timah granite residual soil & Rigid support & 4 & $1.0 \mathrm{He}_{\mathrm{e}}$ to $1.5 \mathrm{He}$ \\
\hline
\end{tabular}

\subsection{Parallel profile and corner effect (3-D behavior)}

To explore the characteristics of three-dimensional deep excavation behaviors, Ou et al. [23] used parametric 3-D finite element calculations. They noticed that the aspect ratio for excavation geometry (B/L) and wall deformation were closely related. Where $\mathrm{B}$ and $\mathrm{L}$ are the horizontal excavation dimensions in the lateral wall deformations and perpendicular directions, respectively. Wall deformations are reduced when the site aspect ratio (B/L) is increased. Furthermore, the wall's deformation is directly proportional to the distance from the wall corner (d). Wall deformation is reduced as the value of (d) decreases. Plane Strain Ratio (PSR) was established by Ou et al. [23]. PSR is defined as the ratio of the maximum wall deformation of the cross-section at a distance $(\mathrm{d})$ from the excavation corner $\left(\delta_{\mathrm{h}-\max }\right)$ to the maximum wall deformation in-plane strain circumstances of the same geometry $\left(\delta_{\mathrm{ps}}\right)$ [50]. Based on the findings of parametric investigations, they developed the relationship between (PSR), site aspect ratio (B/L), and distance from the wall corner (d), as shown in Fig. 8.
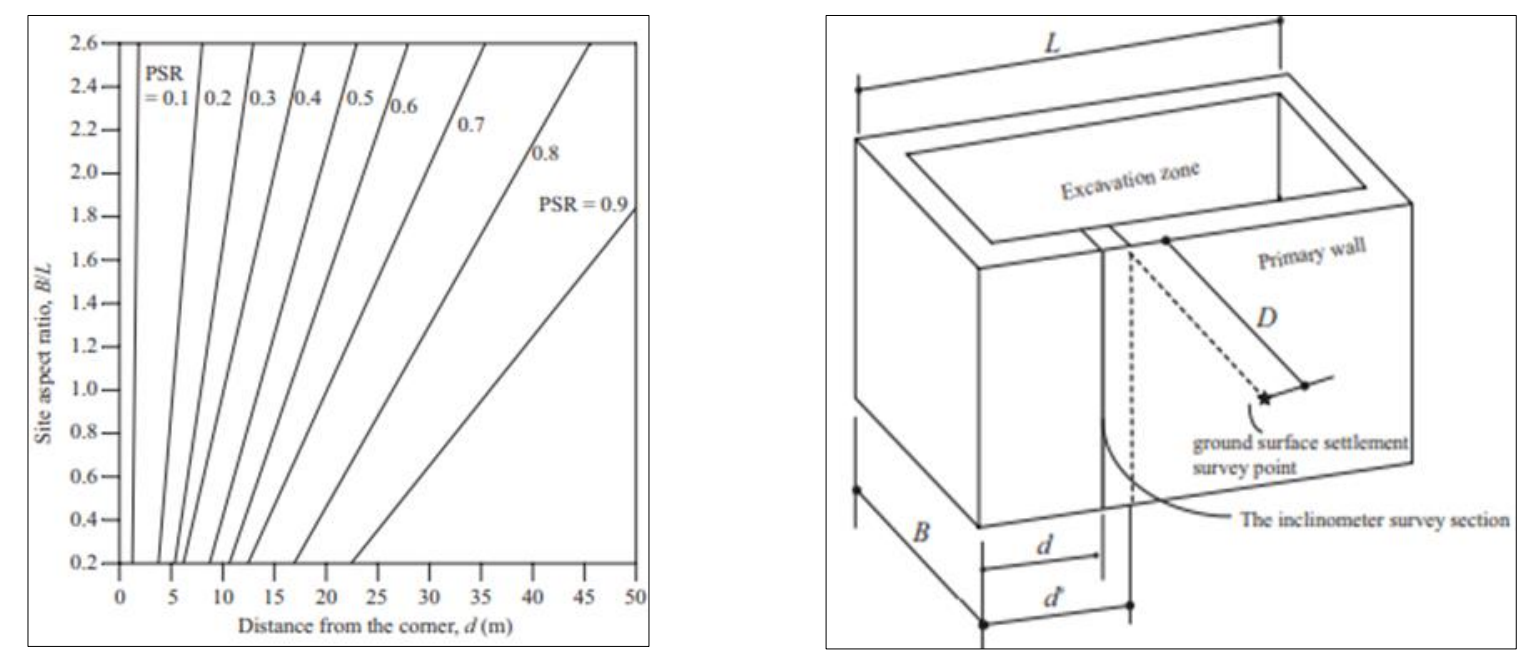

Figure 8 Plane Strain Ratio (PSR) chart [23] 
Finno and Roboski [51], and Roboski and Finno [52] adopted a hypothesis for predicting predict the potential movements of deep excavations in the case of soft to medium clay soils, taking into account the three-dimensional effect of excavation (Fig. 9). The hypothesis was obtained by analyzing and evaluating the data of optical survey for a deep excavation support system (SHPW with three levels of anchors). The results showed that if the complementary error function (ERFC) is used, then only geometry and maximum movement parameters shall be required to define the ground movement pattern. The utilized complementary (ERFC) function is denoted as follows:

$$
\delta(x)=\delta_{\max }\left(1-0.5 \operatorname{erfc} \frac{2.8\left(x+L\left(0.015+0.035 \ln \frac{H_{e}}{L}\right)\right.}{0.5 L-L\left(0.015+0.035 \ln \frac{H_{e}}{L}\right)}\right)
$$

Where $\delta_{\max }$ could refer be either maximum ground settlement $\left(\delta_{\mathrm{v}-\max }\right)$ or maximum lateral deformation $\left(\delta_{\mathrm{h} \text {-max }}\right)$, L is the excavation length, and $\mathrm{H}_{\mathrm{e}}$ is the excavation depth. Whereas this practical approach was developed based on collected data from a flexible support system, it also can forecast potential movement profiles for stiff support systems walls with good accuracy according to Roboski and Finno [52].

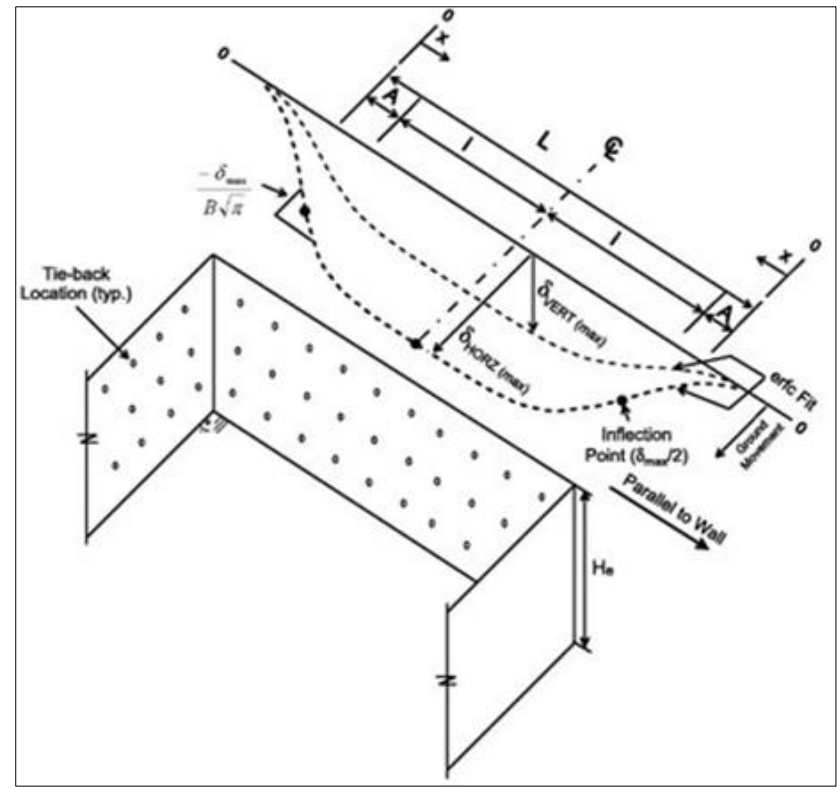

Figure 9 Assumptions of the proposed hypothesis for predicting the movements of deep excavations [52].

The supplementary Error Function method, according to Roboski and Finno [52], is suitable for excavations in which induced ground movement can grow with minimal restriction. Some factors may limit the movement and thus affect its distribution and shape, for example, the presence of utility pipes of large sizes or the presence of deep foundations under the facilities adjacent to the excavation [7]. Therefore, extreme caution should be exercised if the supplementary Error Function (ERFC) method is used in such circumstances.

Wu et al. developed a model that considers the corner effect and 3-D behavior of deep excavation systems based on examining the data from relevant case studies [53]. They found that the location of maximum ground settlement behind the wall $\left(\delta_{\mathrm{v}-\max }\right)$ was approximately at the center of the wall. Furthermore, settlements at the system's corners were reduced owing to the corner effect, and they ranged from $20 \%$ to $60 \%$ of the maximum ground settlement.

Fuentes and Devriendt developed an empirical approach to calculate displacements at the corners of deep excavation systems [54]. According to the results, the distance from the point of maximum ground settlements (wall center), along the wall's two sides, has a linear relationship with the reduction value in the ground settlements. The study showed also that the reduction rate is about 33\%, without considering other factors such as different ground conditions, the quality of the support systems, and the nature of the loads adjacent to the excavation.

Fig. 10 depicts the findings of the ground surface settlement pattern around the excavated zone produced from the 3-D numerical model according to Hefny et al. [10]. They employed contour lines to illustrate the movement pattern. They 
concluded that the lateral wall deformation and ground surface settlement decrease as the distance between the wall corners and cross walls decreases, as illustrated in Fig. 10.

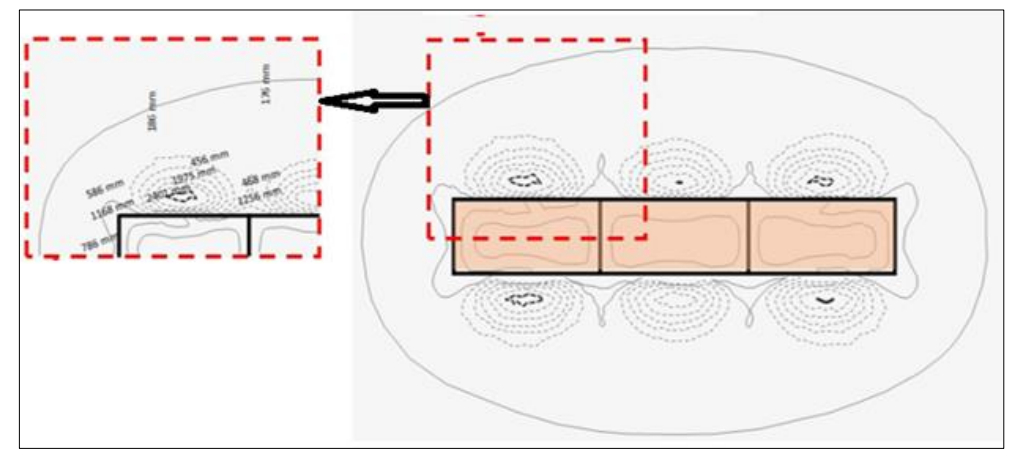

Figure 10 Movement pattern using contour lines around Rod El-Farag metro station (10).

\subsection{Settlement influence zone}

According to Hsieh and $\mathrm{Ou}$, the major influence zone is around two times the excavation depth $\left(2 \mathrm{H}_{\mathrm{e}}\right)$ in width, while settlement is almost non-existent beyond a distance of four excavation depths $\left(4 \mathrm{H}_{\mathrm{e}}\right)$ [24]. Aye et al. investigated the influence area's relation with depth behind the wall and found that the settlement influence area reduces with depth, where its value is $\left(D_{0}\right)$ at the ground surface and almost vanishes at the wall's toe, as illustrated in Fig. 11 [55]. For vertical movement prediction, they considered a linear relationship between the volume of the deformation profile of the wall and the volume of the settlement zone behind the wall at any depth inside the influence zone. They found that the vertical movement can be predicted using this generated polynomial curve. As illustrated in Fig. 11, Aye et al. analyzed the induced settlement that is expected to be mostly linked to wall cantilever mode [55]. The volume of the wall deflection $\left(\mathrm{V}_{\mathrm{o}}\right)$ was obtained by numerically integrating lateral wall deflection using the 1-D beam-spring model. The vertical influence distance was estimated to be $2.5 \mathrm{He}$ at the ground surface behind the retaining wall. As illustrated in Fig. 11, the influence zone area behind the wall was established by drawing a triangle that combines the endpoints of $D_{o}$ and $\mathrm{H}_{\mathrm{w}}$, where $\mathrm{H}_{\mathrm{w}}$ is the wall height. The area of influence is supposed to diminish linearly with the wall depth, achieving maximum value at the ground surface and zero at the wall's toe. Aye et al. presented an approach that may be utilized as a conservative approximation to predict the influence zone, and the accompanying displacement profiles are likewise conservative [55, 56-57]. As for substantial surface displacements $\left(D_{0}\right)$, the maximum distance from the wall might be considered as $2 \mathrm{He}$ for a better match, rather than $2.5 \mathrm{He}$ as proposed by Aye et al. [55,57].

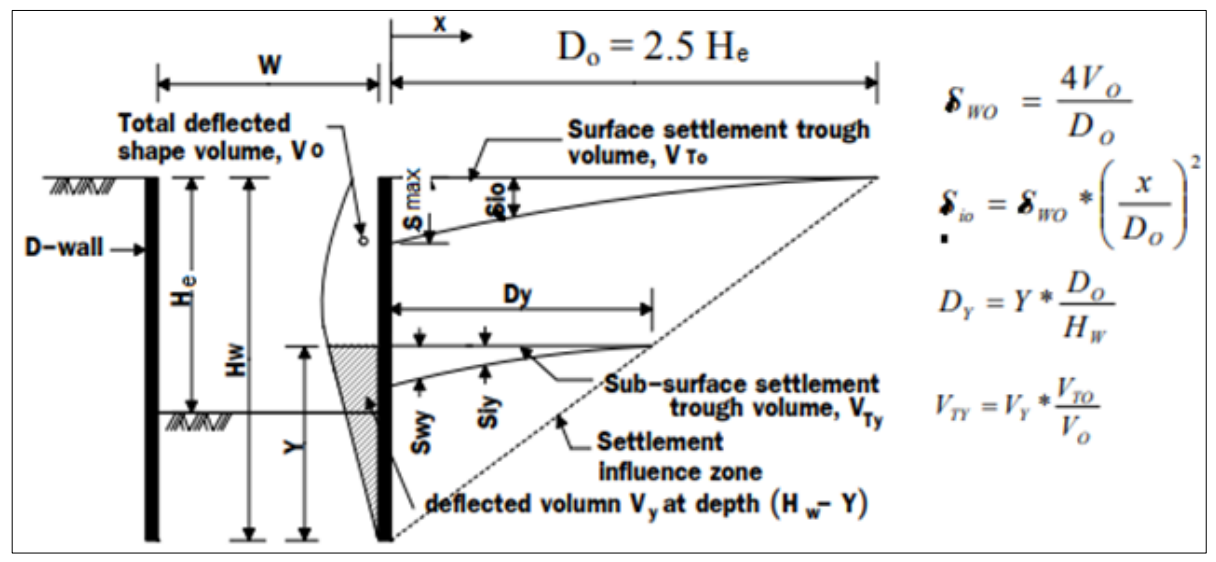

Figure 11 Demonstration of vertical movement prediction for DW [55]

Leung and $\mathrm{Ng}$ [36] collected and evaluated field observation data on lateral wall deformation and ground surface settlement from 14 case studies of deep excavation. They found that the excavation influence zone $\left(D_{0}\right)$ in all groups has a mean value $\left(D_{0}=2.5 H_{e}\right)$, which falls within the values observed in soft clays and sands $\left(D_{0}=2.0 \mathrm{H}_{e}\right)$ and stiff clays $\left(D_{0}=3.0 H_{e}\right)$. Furthermore, they found that when employing a cast-in-situ concrete wall, measured lateral wall deformation and vertical ground settlement are generally unaffected by the system stiffness. 
According to Wang et al. [14], the settlement influence zone $\left(\mathrm{D}_{\mathrm{o}}\right)$ extends from $1.5 \mathrm{H}_{\mathrm{e}}$ to $3.5 \mathrm{H}_{\mathrm{e}}$ from the wall head. They observed that the position of $\delta_{\mathrm{v} \text {-max }}$ is generally within a distance $\left(\mathrm{U}_{\mathrm{v} \text {-max }}=1.0 \mathrm{H}_{\mathrm{e}}\right)$ from the wall. Table 4 summarizes the study authors, ground condition, support type, number of cases, and the width of the influence zone in terms of excavation depth $\left(\mathrm{H}_{\mathrm{e}}\right)$, as measured in worldwide case studies.

Table 4 Summary of the reported influence zone width in terms of excavation depth $\left(\mathrm{h}_{\mathrm{e}}\right)$

\begin{tabular}{|c|c|c|c|}
\hline Study & Ground condition & Support type & Influence zone \\
\hline \multirow{3}{*}{ Peck [45] } & Sands; medium to hard clays & \multirow{3}{*}{ Flexible support } & $2 \mathrm{H}_{\mathrm{e}}$ \\
\hline & Soft clay (limited depth) & & $3.5 \mathrm{He}_{\mathrm{e}}$ \\
\hline & Soft clay (extended) & & $>3.5 \mathrm{He}_{\mathrm{e}}$ \\
\hline \multirow{3}{*}{ O’Rourke [58] } & Dense sands; stiff clays & Flexible support & $2 \mathrm{He}$ \\
\hline & Soft clay (limited depth) & Flexible support & $1.5 \mathrm{He}_{\mathrm{e}}$ \\
\hline & Soft clay (extended) & Flexible support & $>2.2 \mathrm{He}_{\mathrm{e}}$ \\
\hline \multirow{2}{*}{ Goldberg et al. [59] } & Sands, gravels, very stiff to hard clays & \multirow{2}{*}{ Mixed support } & $2 \mathrm{He}_{\mathrm{e}}$ \\
\hline & Soft clays & & $2.5 \mathrm{He}_{\mathrm{e}}$ \\
\hline \multirow{3}{*}{ Clough and O'Rourke [21] } & Sands & \multirow{3}{*}{ Mixed support } & $2 \mathrm{H}_{\mathrm{e}}$ \\
\hline & Stiff clays & & $3 \mathrm{He}_{\mathrm{e}}$ \\
\hline & Soft clays & & $2 \mathrm{He}_{\mathrm{e}}$ \\
\hline Moorman [12] & Soft clay & Mixed support & $2 \mathrm{He}_{\mathrm{e}}$ \\
\hline El-Nahhas [60-61] & Nile alluviums & Rigid support & $1.5-2 \mathrm{He}_{\mathrm{e}}$ \\
\hline \multirow{2}{*}{ Leung and $\mathrm{Ng}[36]$} & Soft clays and sands & \multirow{2}{*}{ Rigid support } & $2 \mathrm{He}$ \\
\hline & Stiff clays & & $3 \mathrm{He}_{\mathrm{e}}$ \\
\hline \multirow{2}{*}{ Abdel-Rahman and El-Sayed [62] } & \multirow{2}{*}{ Nile alluviums } & \multirow{2}{*}{ Rigid support } & $\begin{array}{l}\text { 3.8 He (shallow } \\
\text { found.) }\end{array}$ \\
\hline & & & $\begin{array}{l}2.2 \mathrm{He} \text { (deep } \\
\text { found.) }\end{array}$ \\
\hline Wang et al. [14] & Clays & Mixed support & $1.5-3.5 \mathrm{He}_{\mathrm{e}}$ \\
\hline Zhang et al. [16] & Bukit Timah granite residual soil & Rigid support & $2-3 \mathrm{He}_{\mathrm{e}}$ \\
\hline Hefny et al. [10] & Sandy silty clay, dense to fine sand & Rigid Support & $2 \mathrm{He}_{\mathrm{e}}$ \\
\hline
\end{tabular}

Notes: Flexible support (sheet-pile walls, soldier beam, and lagging); Rigid support (secant pile wall, tangent pile wall, and diaphragm walls).

\section{Relation between $\delta_{\mathrm{h}-\max }$ and $\delta_{\mathrm{v}-\max }$}

The $\delta_{\mathrm{v} \text {-max }}$ value is proportional to $\delta_{\mathrm{h} \text {-max }}$ value, where $\delta_{\mathrm{v} \text {-max }}$ value may be estimated by knowing the $\delta_{\mathrm{h} \text {-max }}$ value according to several researchers $[7,14,42]$. Fig. 12 shows $\delta_{h \text {-max }}$ values versus $\delta_{v \text {-max }}$ both divided by the height excavation $\left(H_{e}\right)$. Hsieh and $\mathrm{Ou}$ [24] compiled the data included in Fig. 12 from a variety of case studies throughout the world and drew on data from both Mana and Clough [31], and Ou et al. [32] (Spandrel type). Equation 2, and Fig. 12 show how $\delta_{\mathrm{v}-m a x}$ values correspond to $\delta_{\mathrm{h}-\max }$ values.

$$
\delta_{\mathrm{v}-\max } \approx 0.50 \delta_{\mathrm{h}-\max } \text { to } 1.0 \delta_{\mathrm{h}-\max }
$$




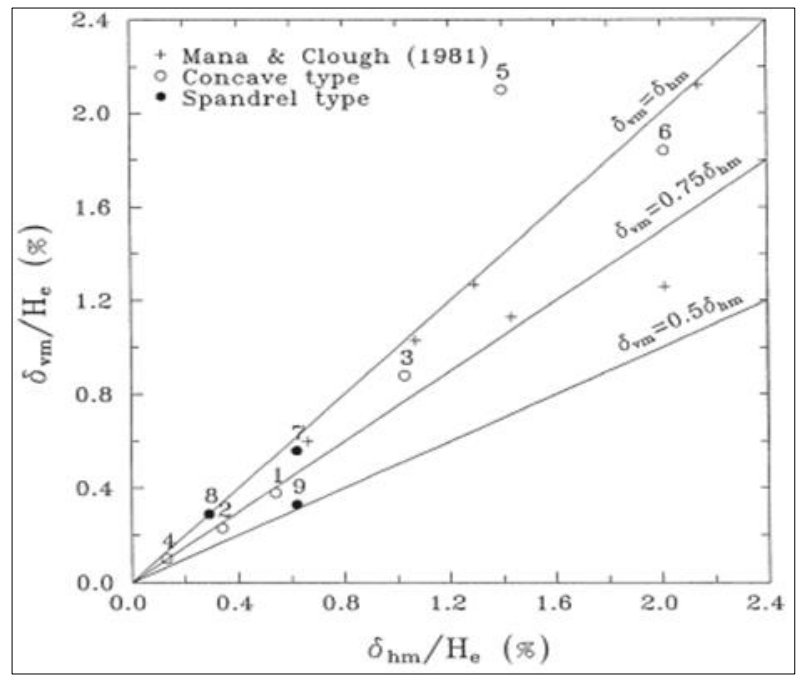

Figure 12 Relation Between $\delta_{\mathrm{h}-\mathrm{max}}$ and $\delta_{\mathrm{v}-\max }$ values according to Hsieh and Ou. [24]

The relation between $\delta_{\mathrm{h}-\max }$ values and $\delta_{\mathrm{v}-\max }$ values according to Wang et al. [14], typically ranges between 0.4 and 2.0 , with a mean value of 0.9 , as illustrated in Fig. 13

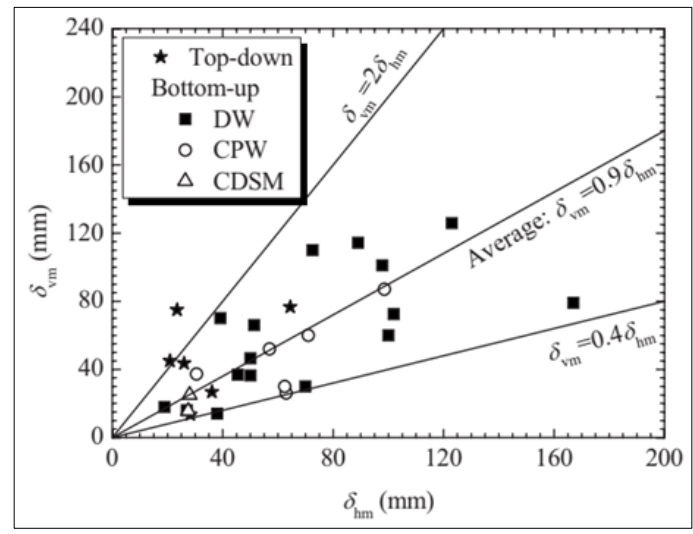

Figure 13 Relation Between $\delta_{\mathrm{h}-m a x}$ and $\delta_{\mathrm{v}-\max }$ values [14]

Deformation characteristics were detected through analyzing the field monitoring data collected from 92 braced excavations in soft soil (China), whereas the excavations were different in terms of width [42]. They concluded that the ratio of $\delta_{\mathrm{v}-\max } / \delta_{\mathrm{h} \text {-max }}$ ranges from the line of $\delta_{\mathrm{v}-\max }=0.2 \delta_{\mathrm{h} \text {-max }}$ to $\delta_{\mathrm{v}-\max }=2.5 \delta_{\mathrm{h} \text {-max }}$, with an average line of $\delta_{\mathrm{v}-\text { max }}=1.25 \delta_{\mathrm{h}-}$ max, as shown in Fig. 14.

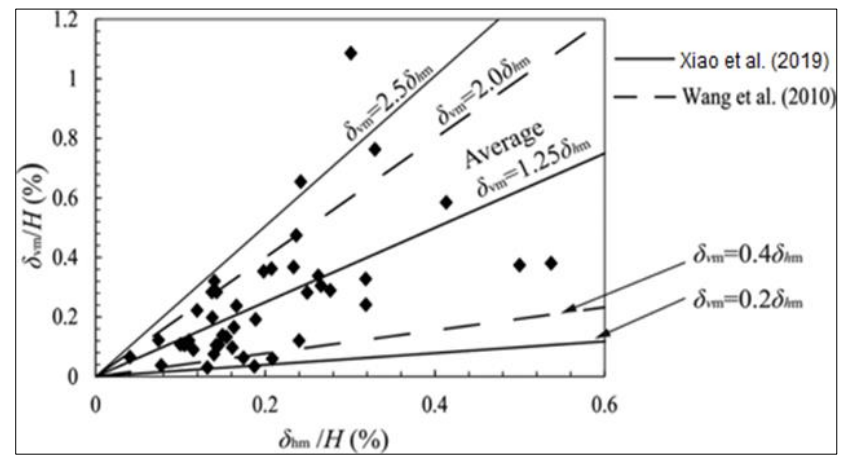

Figure 14 Relation Between $\delta_{\mathrm{h}-m a x}$ and $\delta_{\mathrm{v}-\max }$ values [42] 
Table 5 summarizes the study authors, soil type, wall type, and the reported $\delta_{\mathrm{v} \text {-max }} / \delta_{\mathrm{h} \text {-max }}$ values, as measured in worldwide case studies.

Table 5 Summary of reported relationship between $\delta_{\mathrm{v}-\max }$ and $\delta_{\mathrm{h}-\max }$

\begin{tabular}{|l|l|l|l|}
\hline \multicolumn{1}{|c|}{ Study } & \multicolumn{1}{|c|}{ Soil type } & \multicolumn{1}{c|}{ Wall type } & \multicolumn{1}{c|}{$\boldsymbol{\delta}_{\mathbf{v}-\mathbf{m a x}} / \boldsymbol{\delta}_{\mathbf{h} \text {-max }}$} \\
\hline Mana and Clough [31] & Clay & SHPW & $0.5-1.0$ \\
\hline Ou et al. [32] & Taipei soft clay & DWs “bottom-up method" & $0.5-1.0$ \\
\hline Li [48] & Old alluvium, Singapore & DW & $0.6-1.1$ \\
\hline \multirow{2}{*}{ Leung and Ng [36] } & Soft clays and sands & CW & $0.2-1.2(0.5)$ \\
\cline { 2 - 4 } & Stiff clays & DW, CPW “bottom-up method" & $0.4-2.0(0.9)$ \\
\hline Wang et al. [14] & Shanghai soft soil & - & $0.09-0.18(0.13)$ \\
\hline Wang et al. [49] & Shanghai soft soil & Anchored PW & $0.7-1.4(1.0)$ \\
\hline Ali and Khan [41] & Firm to stiff clay & SPW and DW & $1.0-10.0(3.0)$ \\
\hline Zhang et al. [16] & Bukit Timah granite residual soil & SP) \\
\hline Xiao et al. [42] & Soft soils in China & DW, CPW, SMW, and SHPW & $0.2-2.5(1.25)$ \\
\hline
\end{tabular}

Notes: (1) Sheet Pile Wall (SHPW), Secant Pile Wall (SPW), Contiguous Pile Wall (CPW), Diaphragm Wall (DW), Soil-Nailed Shotcrete Wall (SNSW), Anchored Micro Pile Wall (MPW), Concrete Walls (CW), Deep Soil Mixing (DSM)

\section{Summary statistics}

This paper presented a detailed literature analysis of the general deflection behavior of deep excavation support systems. Normalized horizontal deflection $\left(\delta_{\mathrm{h}-\max } / \mathrm{H} \%\right)$, vertical displacement $\left(\delta_{\mathrm{v}-\max } / \mathrm{H}_{\mathrm{e}} \%\right)$, $\delta_{\mathrm{v} \text {-max }} / \delta_{\mathrm{h}-\max }$ ratio, settlement influence zone of excavations $\left(\mathrm{D}_{\mathrm{o}}\right)$, etc., can play important roles in describing the deflection behavior of a system.

The data was divided into two main categories according to Clough and O’Rourke [21]: (1) Stiff clays, residual soils, and sands, (2) soft to medium clays. Table 6 shows summary statistics of average $\delta_{\mathrm{h}-\mathrm{max}} / \mathrm{H}_{\mathrm{e}}, \delta_{\mathrm{v}-\mathrm{max}} / \mathrm{H}_{\mathrm{e}}$, Influence zone (D/He), and $\delta_{\mathrm{v}-\max } / \delta_{\mathrm{h}-\max }$ values that were reported in the previous literature review.

Table 6 Summary Statistics of average $\delta \mathrm{h}-\max / \mathrm{He}, \delta \mathrm{v}$-max/He, Influence zone (D/He), and $\delta v$-max/ $/ \mathrm{h}$-max ratio values

\begin{tabular}{|c|c|c|c|c|c|c|c|c|}
\hline & \multicolumn{2}{|c|}{ Average $\delta_{h-\max } / \mathrm{H}_{\mathrm{e}}$} & \multicolumn{2}{|c|}{ Average $\delta_{v-\max } / \mathrm{H}_{\mathrm{e}}$} & \multicolumn{3}{|c|}{ Influence zone $\left(\mathrm{D} / \mathrm{H}_{\mathrm{e}}\right)$} & \multirow{2}{*}{$\begin{array}{r}\boldsymbol{\delta}_{\mathrm{v}-\max } / \boldsymbol{\delta}_{\mathrm{h}-\max } \\
\text { Soft Clay }\end{array}$} \\
\hline & $\begin{array}{l}\text { Soft } \\
\text { Clay }\end{array}$ & $\begin{array}{l}\text { Sands and } \\
\text { Stiff Soil }\end{array}$ & $\begin{array}{l}\text { Soft } \\
\text { Clay }\end{array}$ & $\begin{array}{l}\text { Sands and } \\
\text { Stiff Soil }\end{array}$ & Sands & $\begin{array}{l}\text { Soft } \\
\text { Clay }\end{array}$ & $\begin{array}{l}\text { Stiff } \\
\text { Soil }\end{array}$ & \\
\hline Mean & 0.58 & 0.20 & 0.49 & 0.24 & 2.00 & 2.30 & 3.00 & 1.63 \\
\hline St. Error & 0.12 & 0.02 & 0.09 & 0.09 & 0.00 & 0.19 & 0.00 & 0.64 \\
\hline Median & 0.39 & 0.20 & 0.33 & 0.15 & 2.00 & 2.20 & 3.00 & 1.02 \\
\hline Mode & 0.40 & 0.23 & 0.25 & 0.15 & 2.00 & 2.00 & 3.00 & 0.75 \\
\hline St. Dev. & 0.44 & 0.09 & 0.28 & 0.28 & 0.00 & 0.56 & 0.00 & 1.72 \\
\hline Min. & 0.17 & 0.07 & 0.13 & 0.02 & 2.00 & 1.50 & 3.00 & 0.20 \\
\hline Max. & 1.50 & 0.40 & 1.10 & 1.00 & 2.00 & 3.50 & 3.00 & 5.50 \\
\hline Sum & 7.63 & 2.46 & 4.91 & 2.39 & 10.00 & 20.70 & 6.00 & 11.41 \\
\hline Count & 13.00 & 12.00 & 10.00 & 10.00 & 5.00 & 9.00 & 6.00 & 7.00 \\
\hline
\end{tabular}


According to Table 6 , the results for sands and stiff soils showed that $\delta_{\mathrm{h}-\mathrm{max}} / \mathrm{H}_{\mathrm{e}} \%$ and $\delta_{\mathrm{v}-\mathrm{max}} / \mathrm{H}_{\mathrm{e}} \%$ are around 0.20 percent and 0.24 percent, respectively. These values are considered relatively small when compared to soft clays. Where $\delta_{\mathrm{h}}$ $\max / \mathrm{He}_{\mathrm{e}} \%$ has an average value of $0.58 \%$ and $\delta_{\mathrm{v}-\max } / \mathrm{H}_{\mathrm{c}} \%$ has an average value of $0.49 \%$ in the case of soft clay. Also, the settlement influence zone $\left(D_{0}\right)$ reaches a mean distance of $2.3 \mathrm{H}_{\mathrm{e}}$, which falls within $\mathrm{D}_{0}=1.5-3.5 \mathrm{He}_{\mathrm{e}}$ in the case of soft clays, while $\mathrm{D}_{\mathrm{o}}$ reaches a mean distance of $2.0 \mathrm{H}_{\mathrm{e}}$ and 3.0 in the case of sands and other stiff clay soils, respectively. In more depth, it is possible to infer the effect of excavation support system stiffness on both normalized horizontal deflection $\left(\delta_{\mathrm{h}-\max } / \mathrm{H}_{\mathrm{e}} \%\right)$, and vertical displacement $\left(\delta_{\mathrm{v}-\mathrm{max}} / \mathrm{He}_{\mathrm{e}} \%\right)$. Figs. 15 and 16 show $\delta_{\mathrm{h} \text {-max }} / \mathrm{H}_{\mathrm{e}} \%$ values arranged according to the excavation support system stiffness in the case of soft clay and sands and stiff soils, respectively. Also, Figs. 17 and 18 show $\delta_{\mathrm{v}-\mathrm{max}} / \mathrm{H}_{\mathrm{e}} \%$ values arranged according to the excavation support system stiffness in the case of soft clay, sands, and stiff soils, respectively.

In general, the values of horizontal and vertical movement are affected by the excavation support system stiffness. The mean values of normalized horizontal deflection $\left(\delta_{\mathrm{h}-\max } / \mathrm{H}_{\mathrm{e}} \%\right)$ in the case of soft clay are $0.29,0.35$, and 1.41 for rigid, mixed, and flexible support systems, respectively (Fig. 15). While in the case of sands and stiff soils, the mean values of normalized horizontal deflection $\left(\delta_{\mathrm{h}-\max } / \mathrm{H}_{\mathrm{e}} \%\right)$ are 0.17 , and 0.25 for rigid, and mixed support systems, respectively (Fig. 16).

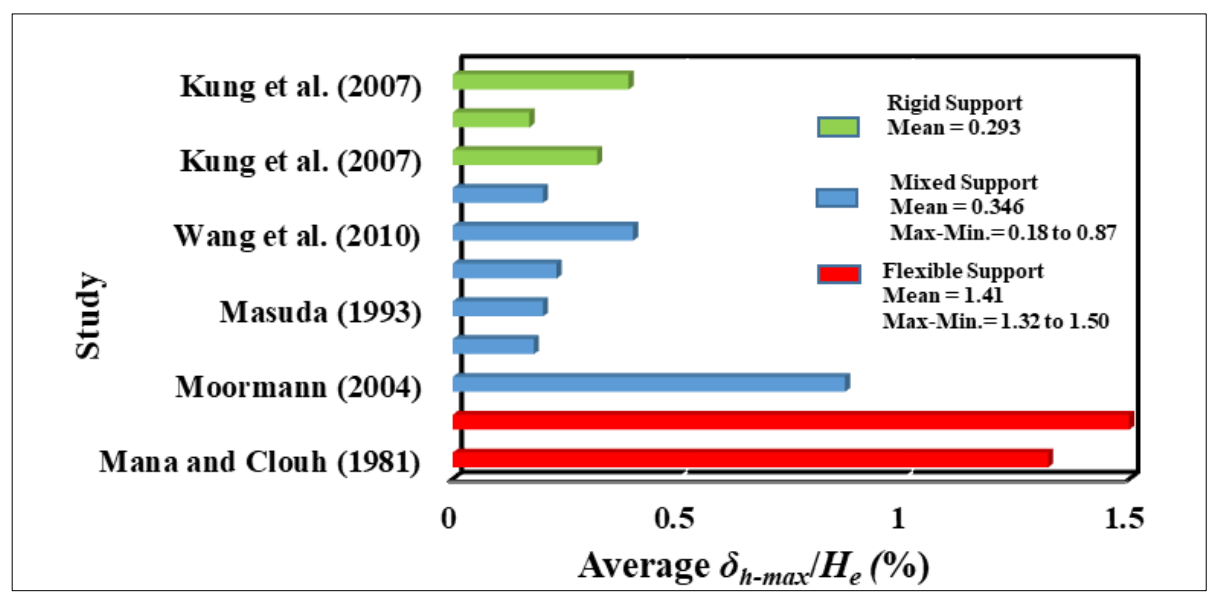

Figure 15 Reported $\delta_{\mathrm{h}-\max } / \mathrm{He}_{\mathrm{e}}$ Values in Worldwide Case Studies in the case of Soft clay soil

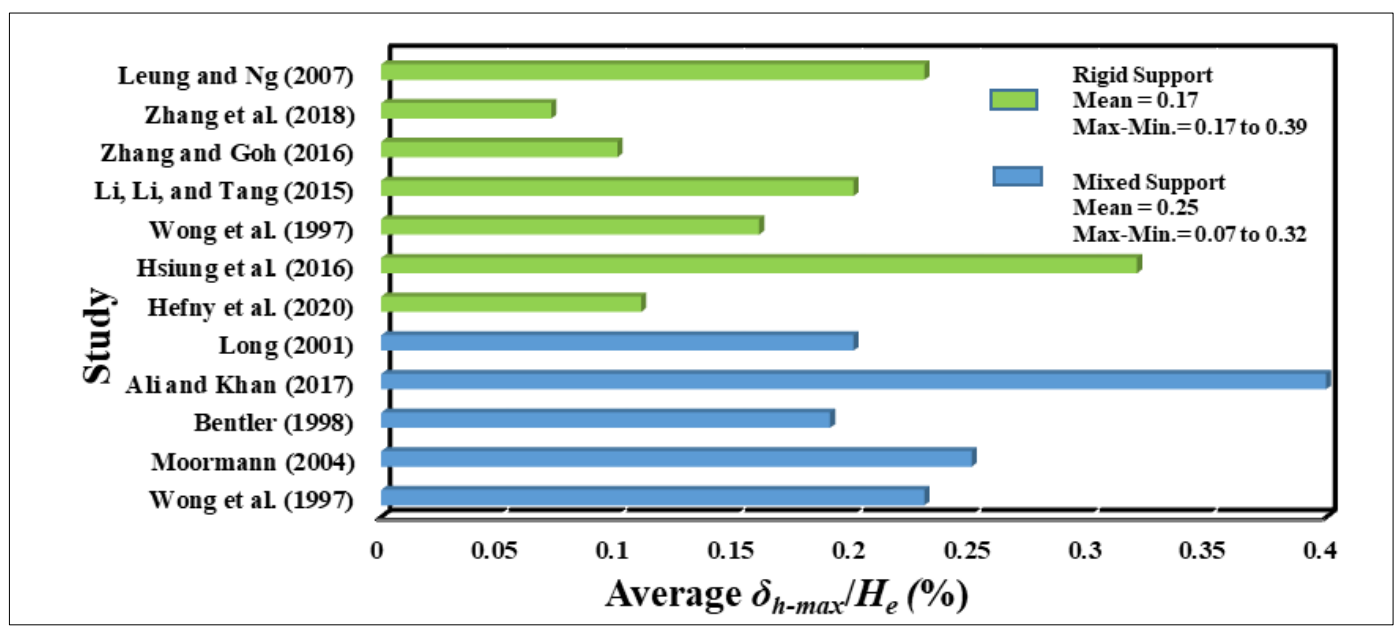

Figure 16 Reported $\delta_{\mathrm{h}-\max } / \mathrm{H}_{\mathrm{e}}$ Values in Worldwide Case Studies in the case of sands and stiff soils

The mean values of normalized vertical deformation $\left(\delta_{\mathrm{v}-\mathrm{max}} / \mathrm{H}_{\mathrm{e}} \%\right)$ in the case of soft clay are 0.37 , and 0.49 for rigid, and mixed support systems, respectively (Fig. 17). While in the case of sands and stiff soils, the mean values of normalized vertical deformation $\left(\delta_{\mathrm{v}-\max } / \mathrm{H}_{\mathrm{e}} \%\right)$ are 0.1 , and 0.18 for rigid, and mixed support systems, respectively (Fig. 18). 


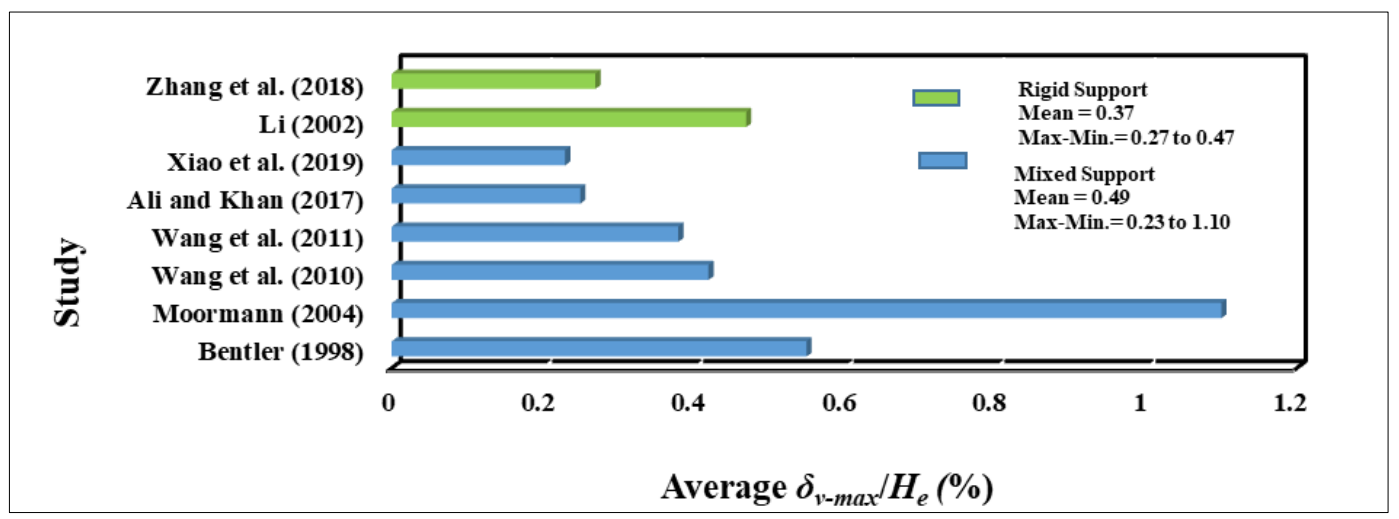

Figure 17 Reported $\delta_{\mathrm{v}-\mathrm{max}} / \mathrm{He}_{\mathrm{e}}$ Values in Worldwide Case Studies in the case of soft clay soil

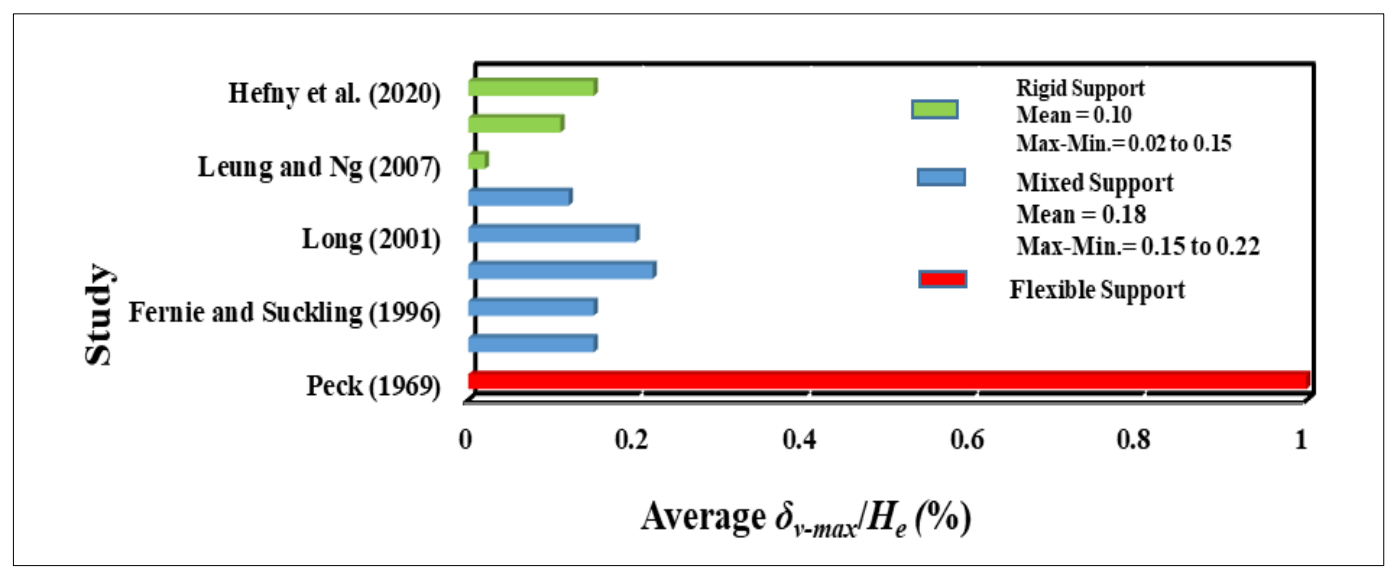

Figure 18 Reported $\delta_{\mathrm{v}-\max } / \mathrm{H}_{\mathrm{e}}$ Values in Worldwide Case Studies in the case of sands and stiff soils

Fig. 19 shows the locations of the maximum ground surface settlement $\left(\boldsymbol{U}_{\boldsymbol{v}-\boldsymbol{m a x}}\right)$ in terms of excavation depth $\left(\mathrm{H}_{\mathrm{e}}\right)$ in the case of soft clay soil. As shown in Fig. 19, $\mathrm{U}_{\mathrm{v}-\max }$ location ranges between $0.50 \mathrm{H}_{\mathrm{e}}$ to $1.25 \mathrm{He}$, with a mean value of $0.81 \mathrm{He}$.

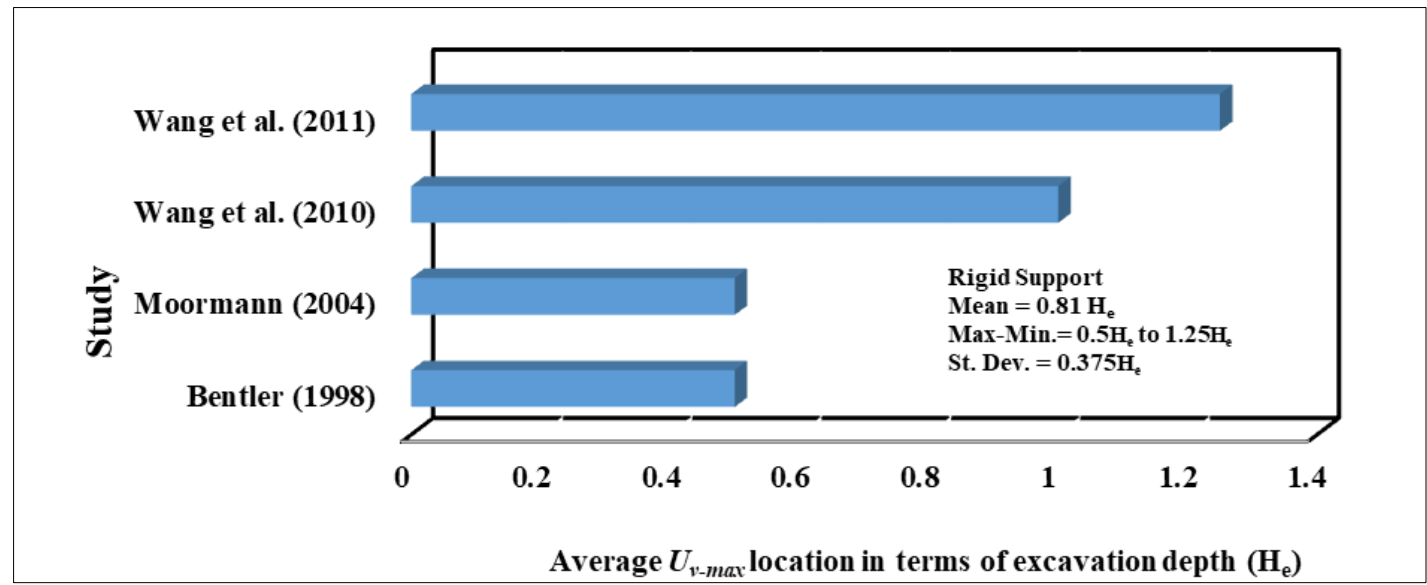

Figure 19 Reported $U_{v-m a x}$ location in terms of excavation depth $\left(\mathrm{H}_{\mathrm{e}}\right)$ in Worldwide Case Studies in the case of soft clay soil

\section{Conclusion}

Based on the reviewed papers and the previous summary statistics, the following conclusions are drawn: 
- The normalized horizontal deflection $\left(\delta_{\mathrm{h}-\max } / \mathrm{He}_{\mathrm{e}} \%\right)$ ranges between 0.17 to 1.5 , with a mean value of 0.58 for soft clay soil, while in the case of sands and stiff clay soils $\delta_{\mathrm{h}-\mathrm{max}} / \mathrm{H}_{\mathrm{e}} \%$ value ranges between 0.07 to 0.40 , with a mean value of 0.20 .

- $\quad$ The normalized vertical displacement $\left(\delta_{\mathrm{v}-\max } / \mathrm{H}_{\mathrm{e}} \%\right)$ ranges between $0.13 \%$ to $1.1 \%$, with a mean value of 0.49 $\%$ for soft soil, while in the case of sands and stiff clay soils $\delta_{\mathrm{v} \text {-max }} / \mathrm{H}_{\mathrm{e}} \%$ value ranges between 0.02 to 1.0 , with a mean value of 0.24 .

- The reported $\delta_{\mathrm{vmax}} / \delta_{\mathrm{hmax}}$ values range between $0.2 \%$ to $5.50 \%$, with a mean value of $1.63 \%$ in the case of soft soil.

- $\quad$ The settlement influence zone of excavations $\left(\mathrm{D}_{0}\right)$ reaches a mean distance of $2.0 \mathrm{H}_{\mathrm{e}}$, which lies between $\mathrm{D}_{0}=1.5$ $3.5 \mathrm{H}_{\mathrm{e}}$ in the case of soft clays. In other stiff clays, $\mathrm{D}_{\mathrm{o}}$ reaches a mean distance of $3.0 \mathrm{H}_{\mathrm{e}}$, while in the case of sands $\mathrm{D}_{\mathrm{o}}$ reaches a mean distance of $2.0 \mathrm{H}_{\mathrm{e}}$.

- $\quad$ Furthermore, the lateral wall deformation reduced as the distance between the wall corners and the cross walls decreased.

- The locations of the maximum ground surface settlement $\left(\boldsymbol{U}_{\boldsymbol{v}-\boldsymbol{m a x}}\right)$ in terms of excavation depth $\left(\mathrm{H}_{\mathrm{e}}\right)$ in the case of soft clay soil ranges between $0.50 \mathrm{H}_{\mathrm{e}}$ to $1.25 \mathrm{H}_{\mathrm{e}}$, with a mean value of $0.81 \mathrm{He}_{\mathrm{e}}$

- In general, the values of horizontal and vertical movement are affected by the excavation support system stiffness. The higher the stiffness of the system, the lower the expected movement.

- The majority of the previous studies had concentrated on wall deformation and ground movement caused by deep excavation in clay, with a particular emphasis on soft clay.

\section{Compliance with ethical standards}

\section{Acknowledgement}

The authors wish to acknowledge the support of Geotechnical Engineering Laboratory Staff, Faculty of Engineering, Kafrelsheikh University, Egypt, in providing the enabling environment for carrying out the research.

\section{Disclosure of conflict of interest}

The authors declared no potential conflicts of interest concerning the research, authorship, and/or publication of this article.

\section{References}

[1] Muñoz-Medina B, Ordóñez J, Romana MG, Lara-Galera A. Typology Selection of Retaining Walls Based on Multicriteria Decision-Making Methods. Applied Sciences. 2021; 11(4), 1457.

[2] O'rourke TD, Jones CJFP. Overview of earth retention systems: 1970-1990. In Design and Performance of Earth Retaining Structures. June 1990; 22-51.

[3] Clayton CR, Woods RI, Milititsky J. Earth pressure and earth-retaining structures. CRC press. 2014.

[4] Azzam WR, Elwakil AZ. Performance of Axially Loaded-Piled Retaining Wall: Experimental and Numerical Analysis. International Journal of Geomechanics. 2017; 17(2): 04016049.

[5] Ramadan MI, Ramadan EH, Khashila MM. Cantilever contiguous pile wall for supporting excavation in clay. Geotechnical and Geological Engineering. 2018; 36(3): 1545-1558.

[6] Finno RJ, Bryson LS. Response of building adjacent to stiff excavation support system in soft clay. Journal of performance of constructed facilities. 2002; 16(1): 10-20.

[7] Zapata-Medina DG. Semi-empirical method for designing excavation support systems based on deformation control. University of Kentucky. 2007.

[8] Mohamad H, Soga K, Pellew A, Bennett PJ. Performance monitoring of a secant-piled wall using distributed fiber optic strain sensing. Journal of Geotechnical and Geoenvironmental Engineering. 2011; 137(12): 1236-1243.

[9] Hsiung BCB. A case study on the behaviour of a deep excavation in sand. Computers and Geotechnics. 2009; 36(4): 665-675.

[10] Hefny A, Al-Atroush ME, Abualkhair M, Alnuaimi MJ. Three-Dimensional Response of the Supported-Deep Excavation System: Case Study of a Large-Scale Underground Metro Station. Geosciences. 2020; 10(2): 76. 
[11] Zahmatkesh A, Choobbast AJ. Evaluation of wall deflections and ground surface settlements in deep excavations. Arabian Journal of Geosciences. 2015; 8(5): 3055-3063.

[12] Moormann C. Analysis of wall and ground movements due to deep excavations in soft soil based on a new worldwide database. Soils and foundations. 2004; 44(1): 87-98.

[13] Kung GT, Juang CH, Hsiao EC, Hashash YM. Simplified model for wall deflection and ground-surface settlement caused by braced excavation in clays. Journal of Geotechnical and Geoenvironmental Engineering. 2007; 133(6): 731-747.

[14] Wang JH, Xu ZH, Wang WD. Wall and ground movements due to deep excavations in Shanghai soft soils. Journal of Geotechnical and Geoenvironmental Engineering. 2010; 136(7): 985-994.

[15] Goh ATC. Deterministic and reliability assessment of basal heave stability for braced excavations with jet grout base slab. Engineering Geology. 2017; 218: 63-69.

[16] Zhang WG, Goh ATC, Goh KH, Chew OYS, Zhou D, Zhang R. Performance of braced excavation in residual soil with groundwater drawdown. Underground Space. 2018; 3(2): 150-165.

[17] Zhao W, Du C, Sun L, Chen X. Field measurements and numerical studies of the behaviour of anchored sheet pile walls constructed with excavating and backfilling procedures. Engineering Geology. 2019; 259: 105165.

[18] Cheng MH, Huang MW, Pan YW, Liao JJ. Lessons from a failure case of an excavated floodway supported by precast cantilever pile walls. Engineering Geology. 2016; 209; 106-118.

[19] Forth RA. Groundwater and geotechnical aspects of deep excavations in Hong Kong. Engineering Geology. 2004; 72(3-4): 253-260.

[20] Pujades E, Vàzquez-Suñé E, Carrera J, Jurado A. Dewatering of a deep excavation undertaken in a layered soil. Engineering geology. 2014; 178: 15-27.

[21] Clough GW, O'Rourke TD. Construction induced movements of insitu walls. Design and performance of earth retaining structures, Geotech. Special Publication No. 25, ASCE, Lambe and L.A. Hansen, eds. $1990 ; 439$ - 470.

[22] Boone SJ, Westland J. Estimating displacements associated with deep excavations. In Geotechnical aspects of underground construction in soft ground. Proceedings of the 5th international conference of TC 28 of the ISSMGE, the Netherlands, 15-17 june 2005; 817-822.

[23] Ou CY, Chiou DC, Wu TS. Three-dimensional finite element analysis of deep excavations. Journal of Geotechnical Engineering. 1996; 122(5): 337-345.

[24] Hsieh PG, Ou CY. Shape of ground surface settlement profiles caused by excavation. Canadian geotechnical journal. 1998; 35(6): 1004-1017.

[25] Hsiao CL. Wall and ground movements in a braced excavation in clays and serviceability reliability of adjacent buildings (Doctoral dissertation, Clemson University). 2007.

[26] Ramadan MI, Meguid M. Behavior of cantilever secant pile wall supporting excavation in sandy soil considering pile-pile interaction. Arabian Journal of Geosciences. 2020; 13(12): 1-13.

[27] Ahmed SM, Fayed AL. Mitigation of Risks Associated with Deep Excavations: State of the Art Review. Proceedings of the Industry Academia Collaboration (IAC 2015), Cairo, Egypt. 2015; 6-8.

[28] Bryson LS, Zapata-Medina DG. Method for estimating system stiffness for excavation support walls. Journal of Geotechnical and Geoenvironmental Engineering. 2012; 138(9): 1104-1115.

[29] Long M. Database for retaining wall and ground movements due to deep excavations. Journal of Geotechnical and Geoenvironmental Engineering. 2001; 127(3): 203-224.

[30] Strom RW, Ebeling RM. State of the practice in the design of tall, stiff, and flexible tieback retaining walls. ENGINEER RESEARCH AND DEVELOPMENT CENTER VICKSBURG MS INFORMATION TECHNOLOGY LAB. 2001.

[31] Mana AI, Clough GW. Prediction of movements for braced cuts in clay. Journal of the Geotechnical Engineering Division. 1981; 107(6): 759-777.

[32] Ou CY, Hsieh PG, Chiou DC. Characteristics of ground surface settlement during excavation. Canadian geotechnical journal. 1993; 30(5): 758-767.

[33] Masuda T. Behavior of deep excavation with diaphragm wall (Doctoral dissertation, Massachusetts Institute of Technology). 1993. 
[34] Wong IH, Poh TY, Chuah HL. Performance of excavations for depressed expressway in Singapore. Journal of geotechnical and geoenvironmental engineering. 1997; 123(7): 617-625.

[35] Bentler DJ. Finite element analysis of deep excavations (Doctoral dissertation, Virginia Polytechnic Institute and State University). 1998.

[36] Leung EH, Ng CW. Wall and ground movements associated with deep excavations supported by cast in situ wall in mixed ground conditions. Journal of geotechnical and geoenvironmental engineering. 2007; 133(2): 129-143.

[37] Li D, Li Z, Tang D. Three-dimensional effects on deformation of deep excavations. Proceedings of the Institution of Civil Engineers-Geotechnical Engineering. 2015; 168(6): 551-562.

[38] Cetin D. Performance of soil nailed and anchored walls based on field monitoring data in different soil conditions in Istanbul. Acta Geotechnica Slovenica. 2016; 13(1): 49-63.

[39] Zhang W, Goh ATC. General behavior of braced excavation in Bukit Timah Granite residual soils: A case study. ISSMGE International Journal of Geoengineering Case Histories. 2016; 3(3): 190-202.

[40] Hsiung BCB, Yang KH, Aila W, Hung C. Three-dimensional effects of a deep excavation on wall deflections in loose to medium dense sands. Computers and Geotechnics. 2016; 80: 138-151.

[41] Ali J, Khan AQ. Behavior of anchored pile wall excavations in clays. Proceedings of the Institution of Civil Engineers - Geotechnical Engineering. 2017; 170(6): 493-502.

[42] Xiao H, Zhou S, Sun Y. Wall deflection and ground surface settlement due to excavation width and foundation pit classification. KSCE Journal of Civil Engineering. 2019; 23(4): 1537-1547.

[43] Lam SY. Ground movements due to excavation in clay: physical and analytical models (Doctoral dissertation, University of Cambridge). 2010.

[44] Goh AT, Chua CG. Geotechnical applications of bayesian neural networks. Metaheuristics Water Geotech Transp Eng. 2013; 271-287.

[45] Peck RB. Deep Excavations and Tunneling in Soft Ground. Proceedings 7th International Conference on Soil Mechanics and Foundation Engineering, State-of-the-Art Volume. 1959; 225-290.

[46] O'Rourke TD. Ground movements caused by braced excavations. Journal of the Geotechnical Engineering Division. 1981; 107(9): 1159-1178.

[47] Fernie R, Sucking T. Simplified approach for estimating lateral wall movement of embedded walls in UK ground. In Geotechnical aspects of underground construction in soft ground. 1996; 131-136.

[48] Li W. Braced excavation in old alluvium in Singapore (Doctoral dissertation, Nanyang Technological University, School of Civil \& Environmental Engineering). 2002.

[49] Wang WD, Xu ZH, Wang JH. Statistical analysis of characteristics of ground surface settlement caused by deep excavations in Shanghai soft soils. Chinese Journal of Geotechnical Engineering. 2011; 33(11): 1659-1666.

[50] Hsiung BCB, Yang KH, Aila W, Ge L. Evaluation of the wall deflections of a deep excavation in Central Jakarta using three-dimensional modeling. Tunnelling and Underground Space Technology. 2018; 72: 84-96.

[51] Finno RJ, Roboski JF. Three-Dimensional Responses of a Tied-Back Excavation through Clay. Journal of Geotechnical and Geoenvironmental Engineering, ASCE. 2005; 131(3): 273-282.

[52] Roboski JF, Finno RJ. Distributions of Ground Movements Parallel to Deep Excavations in Clay. Canadian Geotechnical Journal. 2016; 43(1): 43-58.

[53] Wu CH, Ou CY, Tung N. Corner effects in deep excavations-establishment of a forecast model for taipei basin T2 zone. Journal of Marine Science and Technology. 2010; 18(1): 1.

[54] Fuentes R, Devriendt M. Ground movements around corners of excavations: empirical calculation method. Journal of geotechnical and geoenvironmental engineering. 2010;136(10):1414-1424.

[55] Aye ZZ, Karki D, Schulz C. Ground movement prediction and building damage risk-assessment for the deep excavations and tunneling works in Bangkok subsoil. In International Symposium on Underground Excavation and Tunnelling. 2006; 281: 297.

[56] Korff M, Mair RJ, Van Tol AF. Ground displacements related to deep excavation in Amsterdam. In Proc., 18th Int. Conf. on Soil Mechanics and Geotechnical Engineering. 23 January; 2779-2782. 
[57] Korff M, Mair RJ, Van Tol FA. Pile-soil interaction and settlement effects induced by deep excavations. Journal of Geotechnical and Geoenvironmental Engineering. 2016; 142(8): 04016034.

[58] O'rourke TD, Cording EJ, Boscardin M. The ground movements related to braced excavation and their influence on adjacent buildings. 1976.

[59] Goldberg DT, Jaworski WE, Gordon MD. Lateral Support Systems and Underpinning. Volume I: Design And Construction. 1976.

[60] El-Nahhas F. Construction monitoring of urban tunnels and subway stations. Tunnelling and underground space technology. 1992; 7(4): 425-439.

[61] El-Nahhas FM. Tunnelling and supported deep excavations in the Greater Cairo. In Keynote Paper at the Int. Symposium on Utilization of Underground Space in Urban Areas. International Tunnelling Association \& Egyptian Tunnelling Society, Sharm El-Sheikh, Egypt. 2006; 27-56.

[62] Abdel-Rahman AH, El-Sayed SM. Foundation subsidence due to trenching of diaphragm walls and deep braced excavations in alluvium soils. In Proceedings of the 17th International Conference on Soil Mechanics and Geotechnical Engineering. 1, 2, 3 and 4). 2009; 1935-1938. 